\title{
NUCLEAR CRITICALITY SAFETY EVALUATION OF LARGE CYLINDER ClEANING OPERATIONS IN X-705, PORTSMOUTH GASEOUS DIFFUSION PLANT
}

M. K. SHEAFFER, S. C. KEETON, H. F. LUTZ

Lawrence Livermore National Laboratory

Livermore, California

June 1995

\%ESSP

Fission Energy and Systems Safety Program

Lawrence Livermore National Laboratory

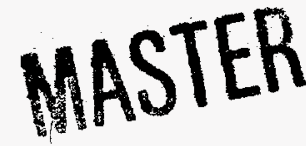
DISTRIBUTION OF THIS DOCUMENT IS UNLIMITED 


\section{DISCLAIMER}

This document was prepared as an account of work sponsored by an agency of the United States Government. Neither the United States Covernment nor the University of California nor any of their employees, makes any warranty, express or implied, or assumes any legal liability or responsibility for the accuracy, completeness, or usefuiness of any information, apparatus, product, or process disclosed, or represents that its use would not infringe privately owned rights. Reference herein to any specific commercial product, process, or service by trade name, trademark, manufacturer, or otherwise, does not necessarily constitute or imply its endorsement, recommendation, or favoring by the United States Government or the University of California. The views and opinions of authors expressed herein do not necessarily state or reflect those of the United States Government or the University of California, and shall not be used for advertising or product endorsement purposes.

This report has been reproduced directly from the best available copy.

Available to DOE and DOE contractors from the

Office of Scientific and Technical Information

P.O. Box 62, Oak Ridge, TN 37831

Prices available from (615) 576-8401, FTS 626-8401

Available to the public from the

National Technical Information Service

U.S. Department of Commerce

5285 Port Royal Rd.

Springfield, VA 22161

Work performed under the auspices of the U.S. Department of Energy by Lawrence Livermore National Laboratory under Contract W-7405-ENG-48. 


\section{DISCLAIMER}

Portions of this document may be illegible in electronic image products. Images are produced from the best available original document. 
NUCLEAR CRITICALITY SAFETY EVALUATION OF LARGE CYLINDER CLEANING OPERATIONS IN X-705, PORTSMOUTH GASEOUS DIFFUSION PLANT

M. K. SHEAFFER

S. C. KEETON

H. F. LUTZ

June 1995 


\begin{abstract}
This report evaluates nuclear criticality safety for large cylinder cleaning operations in the Decontamination and Recovery Facility, X-705, at the Portsmouth Gaseous Diffusion Plant. A general description of current cleaning procedures and required hardware/equipment is presented, and documentation for large cylinder cleaning operations is identified and described. Control parameters, design features, administrative controls, and safety systems relevant to nuclear criticality are discussed individually, followed by an overall assessment based on the Double Contingency Principle. Recommendations for enhanced safety are suggested, and issues for increased efficiency are presented.
\end{abstract}




\section{TABLE OF CONTENTS}

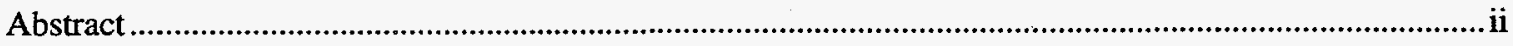

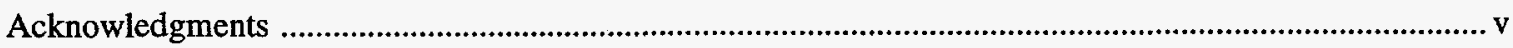

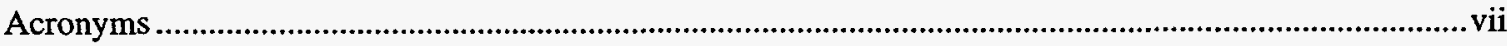

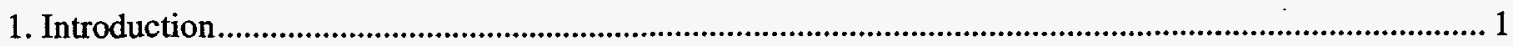

2. Summary

3. Description Of Large Cylinder Cleaning Operations .............................................................................. 7

3.1 Procedures and Equipment .........................................................................................................

3.2 Input and Output Streams of Fissile Material .................................................................................

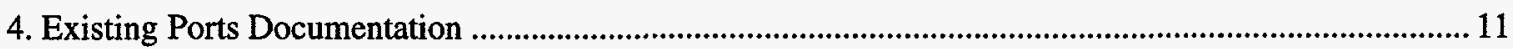

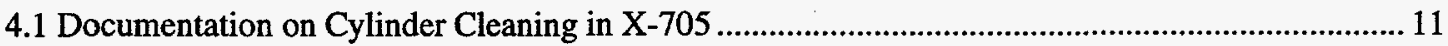

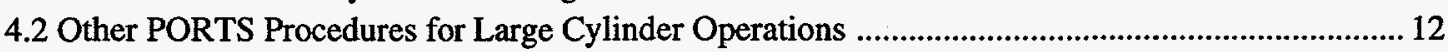

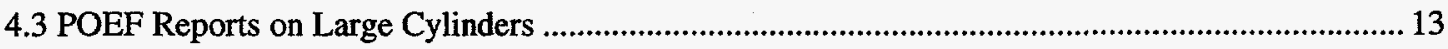

5. Control Parameters, Design Features, Administrative Controls, and Safety Systems..............................15

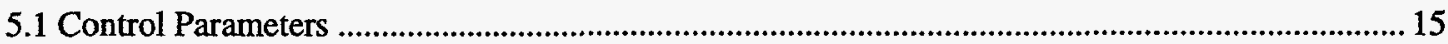

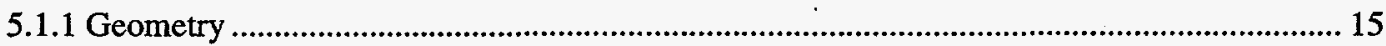

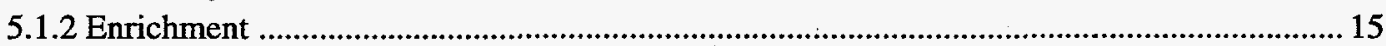

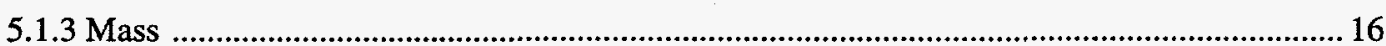

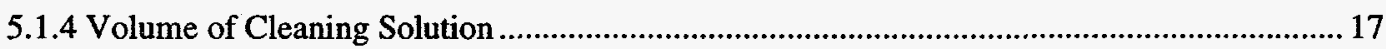

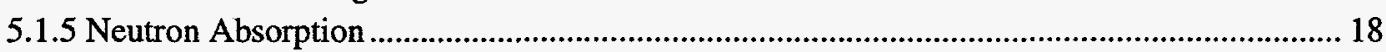

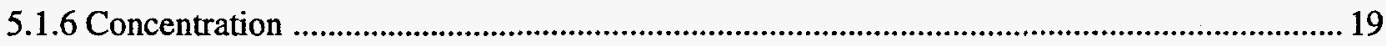

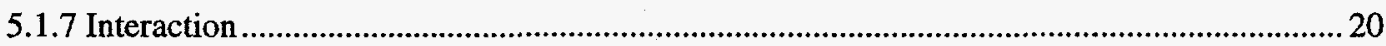

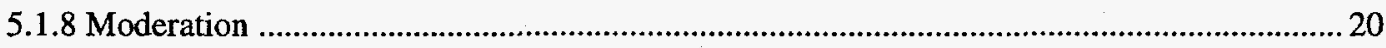

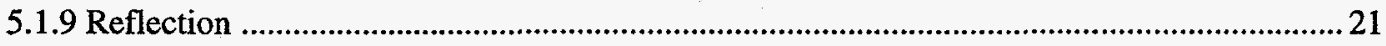

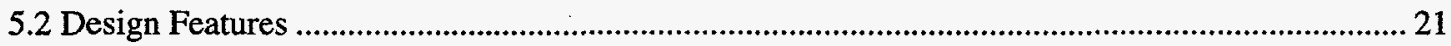

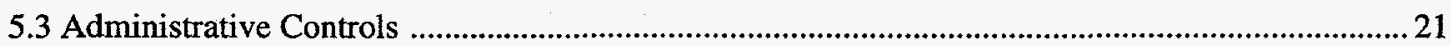

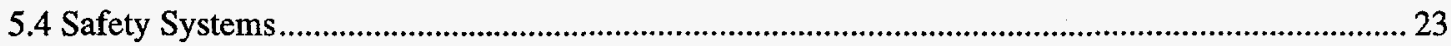

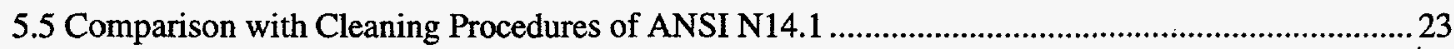

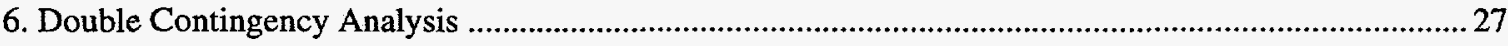

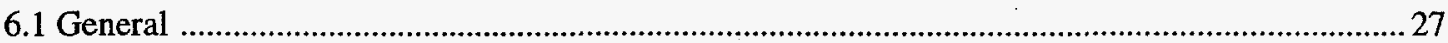

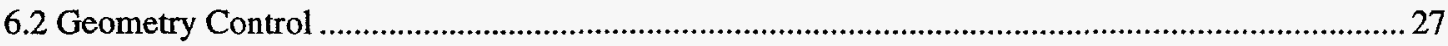

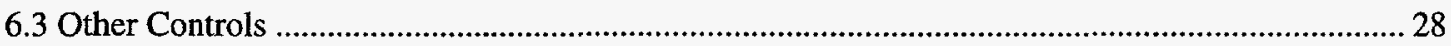

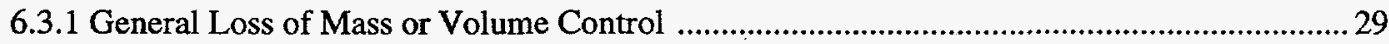

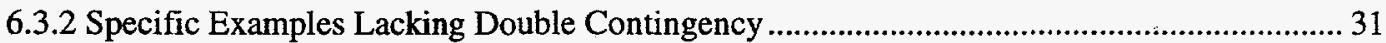

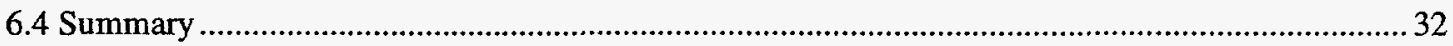

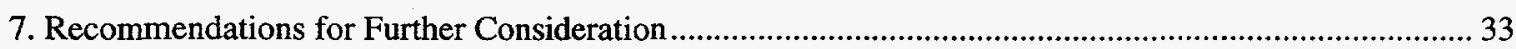

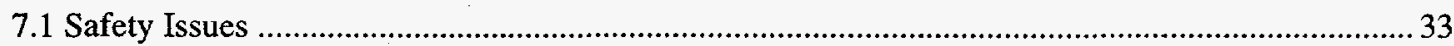

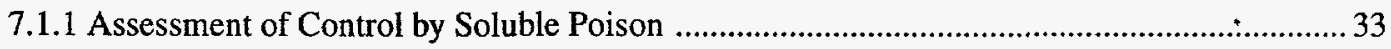

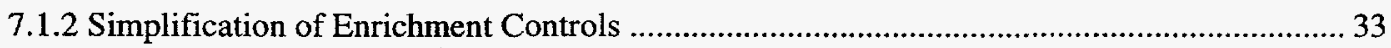

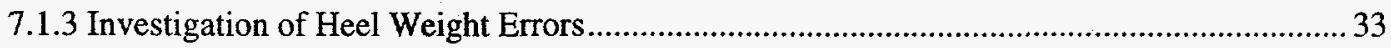

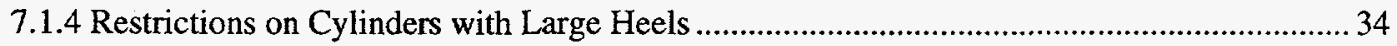

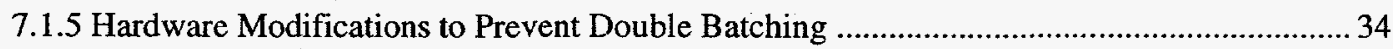

7.1.6 Further Evaluation of Double Batching Accident ................................................................. 34

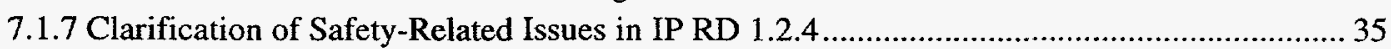

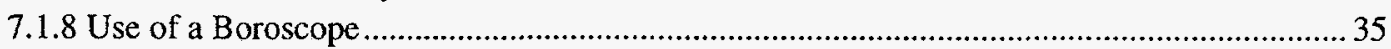

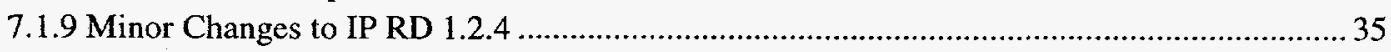




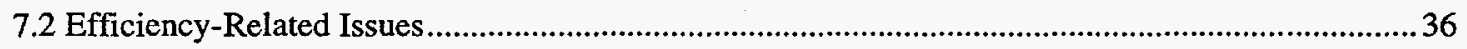

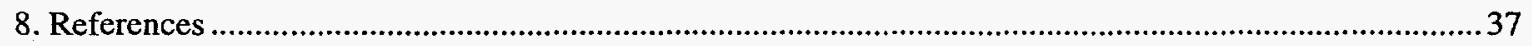

Appendix A: Flowcharts of Large Cylinder Cleaning Procedures .........................................................39

\section{TABLES}

Table 1.1 Breakdown of X-705

Table 5.1 Maximum heel weight limits from IP RD 1.2.4, Rev. 4, Ch. A-C ............................................16

Table 5.2 Maximum cleaning solution for heel weights less than $41 \mathrm{lb}$....................................................18

Table 5.3 Administrative controls for large cylinder cleaning................................................................22

Table 5.4 Comparison of procedures of ANSI N14.1 Appendix B and IP RD 1.2.4 ..............................2 24

Table 6.1 Credible Events Resulting in Loss of Enrichment, Mass, or Volume Control during Large

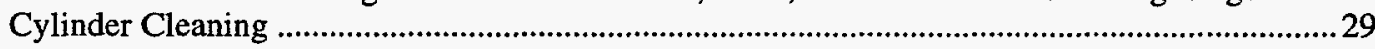

\section{FIGURES}

Figure 3.1 Schematic of large cylinder cleaning operations ......................................................................... 8

Figure 3.2 Schematic of input and output fissile streams for large cylinder cleaning operations .................10

Figure A.1. Determining allowed heel weight in cylinder to be cleaned........................................................40

Figure A.2. Determining allowed volume of cleaning solution. .................................................................. 41

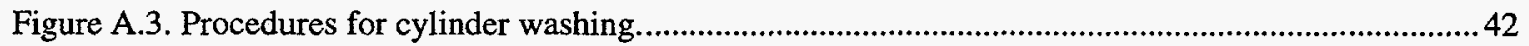

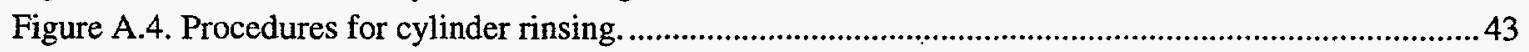




\section{ACKNOWLEDGMENTS}

We would like to thank the numerous PORTS personnel who assisted in the collection of information for this report and who took time from their busy schedules to acquaint us with the operations in X-705. This report would not have been possible without the cooperation of Rob Oxenham and Donna D'Aquila of the PORTS NCS Department. Specific recognition should also be given to the X-705 staff, who had to deal with us on many occasions for several days at a time while we attempted to learn the complex operation of their facility. Melody Channel's support of our administrative and logistical requirements was truly outstanding. D.D. Atkins, Kevin Clausing, Karen Foster, John Oppy, Rudy Spaeth, Bob Stanley, John Urik, Greg Wells, and Jeff Woodard played a significant role in explaining X-705 operations and in providing valuable insight on the day-to-day activities of this many-faceted facility.

Finally, we wish to acknowledge the support we received from the MMES staff at Oak Ridge, particularly Tom Lemons, Curtis Jordan, and Howard Dyer, and Karen Shaffer. 


\section{ACRONYMS}

ANSI

ANT

DOE

DM

DYMCAS

FA

FCA

FSAR

GAT

GDP

HEU

IP

LEU

LLNL

MSDS

MMES

NCS

NCSA

NCSE

PGDP

PORTS

OA

OGRU

$\mathrm{OM}$

OSR

S

SS

UES
American National Standards Institute

Applied Nuclear Technology

Department of Energy

Development Memo

Dynamic Material Control Accounting System

Field Agreement

Facility Change Agreement

Final Safety Analysis Report

Goodyear Atomic Corporation

Gaseous Diffusion Plant

Highly Enriched Uranium

In Hand Procedure (formerly OM)

Low Enriched Uranium

Lawrence Livermore National Laboratory

Material Safety Data Sheet

Martin Marietta Energy Systems, Inc.

Nuclear Criticality Safety

Nuclear Criticality Safety Approval

Nuclear Criticality Safety Evaluation

Paducah Gaseous Diffusion Plant, Paducah, Kentucky

Portsmouth Gaseous Diffusion Plant, Piketon, Ohio

Operational Area

Oil and Grease Removal Unit

Operating Method

Operational Safety Requirement

System

Subsystem

Uranium Enrichment Support 


\section{INTRODUCTION}

As part of its overall Uranium Enrichment Support (UES) Project, the Department of Energy (DOE) tasked Lawrence Livermore National Laboratory in 1991 to provide nuclear criticality safety (NCS) support to the gaseous diffusion plants (GDPs), operated by Martin Marietta Energy Systems (MMES), near Portsmouth, Ohio, and Paducah, Kentucky. One requirement of this GDP NCS Task, as defined by MMES, was a criticality evaluation of the Decontamination and Uranium Recovery Facility, X-705, at the Portsmouth Gaseous Diffusion Plant (PORTS).

This report is one of several documents that evaluates nuclear criticality safety in X705. The initial report ${ }^{1}$ presented a general overview of the facility and provided a breakdown of X-705 into systems, subsystems, and operational areas. This document evaluates in detail the specific operational area of large cylinder cleaning, identified as [OA1.2.1] in Ref. 1. For convenience, the breakdown of X-705 is repeated as Table 1.1 of this report. (During the past three years MMES has somewhat modified the detailed breakdown of operations in X-705. Nevertheless, for consistency with earlier reports, Table 1.1 uses the organization in effect at the time that Ref. 1 was prepared.)

A draft version of this report was originally prepared in 1992 and circulated for review and comment. Because of higher priority tasks, LLNL was requested to complete evaluations of other areas, and a final document on large cylinder cleaning was not prepared prior to termination of the GDP NCS Task in 1993. When LLNL support to PORTS resumed in 1995 under a different program, MMES requested that the evaluation of large cylinder cleaning be updated and published for reference. Several issues affecting criticality safety were identified in the original draft, and many of these concerns are still unresolved. As a result, a primary objective of this report is to document these issues so that they can be resolved in accordance with MMES priorities.

As used in PORTS operations, the term "large cylinders" includes both 30 -in. diameter cylinders, which can contain (nominally) 2.5 tons of uranium hexafluoride $\left(\mathrm{UF}_{6}\right)$, and 48 -in. diameter cylinders, which can contain either 10 or 14 tons, depending on the specific model. The cleaning of these large cylinders presents a unique challenge for criticality safety. As will be discussed in this report, these cylinders contain only low enriched uranium (LEU), and the mass required to achieve a critical reaction is rather large. On the other hand, cleaning of large cylinders is perhaps the only operation in which water is intentionally added to an unfavorable geometry known to contain an uncertain quantity of enriched uranium. In addition, the minimum critical mass of cylinder contents $(\sim 100 \mathrm{lbs}$.), although large by some standards, is less than $1 \%$ of the full contents of the large cylinders.

Section 2 summarizes the top-level conclusions of this evaluation. A general description of large cylinder cleaning procedures and hardware required is presented in Section 3. Section 4 identifies and discusses current NCS documentation applicable to large cylinder cleaning. Section 5 assesses in detail the NCS control parameters and develops consolidated lists of design features, administrative controls, and safety systems. An overall assessment of criticality safety, based on the Double Contingency Principle, is examined in Section 6, and recommendations for further consideration are suggested in Section 7. 


\section{SYSTEM/ SUBSYSTEM/ OPERATIONAL AREA}

1.0 Decontamination (High Bay)

1.1 Large Parts Disassembly \& Decontamination (C Area)

1.1.1 Compressor Disassembly

1.1.2 Converter Disassembly

1.1.3 South Annex Operations

1.1.4 Spray Booth Operations

1.1.5 Truck Alley Cleaning

1.1.6 General Storage and Handling

1.2 Small Parts Cleaning (A Area)

1.2.1 30-in. and 48-in. Cylinder Cleaning

1.2.2 8-in. and 12-in. Cylinder Cleaning

1.2.3 5-in. Cylinder Cleaning

1.2.4 Cylinder Drying, Conditioning, and Testing

1.2.5 Sodium Fluoride Pellet Conditioning

1.2.6 Seal and Small Parts Dismantling

1.2.7 Small Parts Handtable Operations

1.2.8 Small Parts Pit Operations

1.2.9 Sand and Glass Blasting

1.2.10 General Storage and Handling

1.2.11 Trichloroethylene Degreasing

\subsection{Vacuum Cleaners}

$2.0 \quad$ Uranium Recovery (B Area)

2.1 Mixed Acids Precipitation (A Area)

2.2 Trap Material Leaching

2.2.1 Spray Tank Operations (A Area)

2.2.2 Flocculating Columns/Vacuum Filter Table

2.2.3 Unmeasured Storage

2.3 Fluorides-Complexing Handtable (A Area)

2.4 Recovery/Blending Handtable Operations

2.5 Measured Solution Storage (B-36, B-38, B-1)

2.6 Volume Reduction/Chemical Processing

2.7 Calciners 
Table 1.1 Breakdown of X-705 (continued)

\section{SYSTEM/ SUBSYSTEM/ OPERATIONAL AREA}

2.0 Uranium Recovery (B Area)-(cont.)

2.8 Nitrogen Oxide Scrubbers

2.9 Raffinate Storage

2.10 Heavy Metals Precipitation

2.11 Technetium Ion Exchange

2.12 General Storage and Handling

2.13 Continuous Dissolver

2.14 Mixed Acids Precipitation (B Area)

2.15 Neutralization System

2.16 Incinerator

3.0 Oxide Conversion (E/F/H Area)

3.1 UNH Calciner (F Area)

3.2 General Storage and Handling

4.0 Waste Water Treatment Systems

4.1 Condensate Recovery

4.2 Rinse Booth Recirculating Storages

4.3 Cylinder Solution Microfiltration

4.4 Oil and Grease Removal Unit

4.5 Solution Collection and Storage

4.6 Microfiltration/Pressure Filtration

4.7 Effluent Pumping Station

4.8 Tunnel Sumps

4.9 General Storage and Handling

5.0 Support Areas

5.1 Maintenance Shop (D Area)

5.2 Process Laboratory (G Area)

5.3 Laundry

5.4 Office Area

5.5 Acid/Solvent Receiving, Storage, Transfer (H Area)

5.6 Ventilation, Exhaust, and Utilities

5.7 Drains

5.8 General Storage and Handling

5.9 Miscellaneous

Notes:

(1) Systems, subsystems, or operational areas that are no longer operational are indicated with italics.

(2) A category of "General Storage and Handling" has been added to various systems and subsystems to include activities that are difficult to assign specifically to a given area. 


\section{SUMMARY}

Although current procedures for large cylinder cleaning implement an extensive degree of precaution, they do not rigorously satisfy the requirements of the Double Contingency Principle. Criticality control is based on limiting the mass of the cylinder heel and the volume of cleaning solution. Various administrative and human errors that do not meet the criteria of "unlikely events" could result in loss of these controls. Unresolved issues concerning the use of boric acid solution currently negate its qualification as an additional control.

Numerous suggestions are recommended for enhancing criticality safety. The most important ones are summarized below:

- The unresolved issues related to the use of boric acid solution should be addressed at the earliest possible time. The questionable utility of boron poison as a control is a major uncertainty in the criticality analysis. If the boron can be qualified as a control parameter, the safety of large cylinder cleaning increases significantly.

- Complex mass and volume controls are based on enrichment data that could be either erroneous or misinterpreted by operational personnel. A better balance between operational flexibility and criticality safety should be implemented.

- Significant discrepancies in heel masses from DYMCAS records have been identified. The cause of these discrepancies should be investigated, and their impact on procedures for criticality safety addressed. Check-weighing the cylinder immediately prior to cleaning should be considered.

- Double batching of cleaning solution can result from the operator's misunderstanding procedures or his inattentiveness in their implementation. Hardware alternatives that inhibit double batching should be investigated. 


\section{DESCRIPTION OF LARGE CYLINDER CLEANING OPERATIONS}

This section presents a summary of large cylinder cleaning operations, the equipment used in these operations, and the input/output streams of fissile material. Detailed, stepby-step procedures are presented in the In-Hand Procedure RD 1.2.4, Rev. 4, Ch A-C ${ }^{2}$. A flowchart of these procedures is depicted in Appendix A of this report.

The three lettered changes (A, B, and C) have been added to this In-Hand Procedure (IP) since the original draft of this document was prepared. The majority of these changes were either editorial or relevant to cylinder drying operations using the AlwaysSafe Vacuum Cleaner, and hence appear to have no significant impact on criticality. A minor modification to the maximum allowed concentration of uranium before rinsing operations can begin was implemented in Change B and has been incorporated into this report.

According to the PORTS NCS staff, IP 1.2.4 is again under revision. Changes that might result in criticality issues from this revision have not been examined and are not considered in this report.

\subsection{Procedures and Equipment}

Decontamination of large cylinders takes place in the Small Parts, or "A," area of X705. Even though these cylinders are usually "empty," they generally contain a small mass, or heel, of $\mathrm{UF}_{6}$ and nonvolatile uranium products. Situations that would require cylinder decontamination include hydrostatic testing (generally every five years), maintenance, excessive build-up of impurities, and filling with a different assay of uranium.

The equipment and hardware needed for cylinder cleaning are illustrated schematically in Figure 3.1. A large ( $\sim 50$-gallon), open mixing tank is used to prepare a boric acid solution at a concentration of about 0.5 pounds of $\mathrm{H}_{3} \mathrm{BO}_{3}$ crystals per gallon of water ( 10 grams of boron per liter). To the north of this tank are three 6-in. diameter, approximately 8-gallon, unreflected clear glass columns. Column A is used for gravity feeding of clean boric acid solution to the cylinder. Contaminated solution is withdrawn into Column C.

The cylinder to be cleaned is placed on one of two turning fixtures by an overhead crane. A printout of the heel weight and assay are obtained from the Dynamic Material Control and Accounting System (DYMCAS), and these data, along with other information, are recorded on the cylinder cleaning form. If the assay is above 5\% (which is essentially never the case), procedures require a Field Agreement before cleaning. If the assay is less than 5\% and the heel weight is below specified limits (discussed in Section 5.1.3), cleaning procedures can begin. 


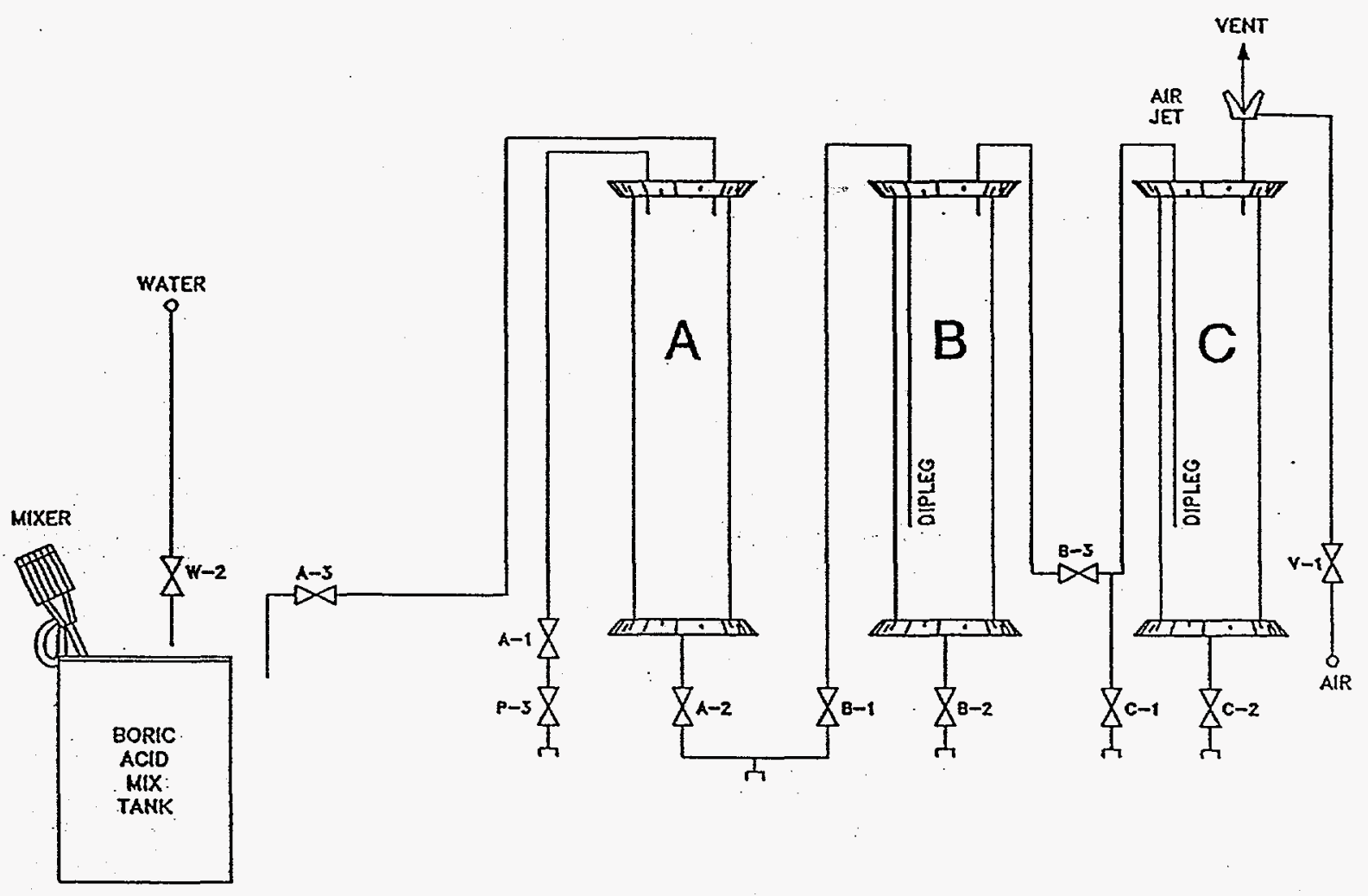

Figure 3.1 Schematic of large cylinder cleaning operations 
A cylinder pressure check is performed by installing a pressure gauge adapter on the cylinder valve port. If the cylinder is at a positive pressure, a transfer line is attached to the adapter, and the cylinder is vented through a boric acid solution in Column B, which is also partially filled with raschig rings (to promote scrubbing). An air-jet is then used to pull a vacuum on the cylinder, and five gallons of boric acid solution are drained from Column A into the cylinder. (In some situations, discussed later in Section 5.1.4, an additional five gallons or more of wash solution may be added.) After the turning fixture rotates and tilts the cylinder for a 30- to 45-minute wash cycle, the cylinder valve is removed, and the contaminated solution is withdrawn with the air-jet into Column $\mathrm{C}$. This solution is then drained from Column $\mathrm{C}$ into polybottles, located on a multi-position cart. (When all bottles on the cart are filled, it is taken to the red spot at the fluoridescomplexing handtable and parked.)

The washing sequence is repeated at least three times. (In practice, ten washes are not unusual.) When the color of the solution indicates that it is rather uncontaminated, a sample is taken to the X-705 laboratory. If the uranium concentration is less than 1000 ppm, the washing process is complete and rinsing can begin.

The rinse process is similar to that of washing except that boric acid solution is not used. Five gallons of clean water are transferred into Column $\mathrm{C}$ and drained into the cylinder, and the turning fixture is operated for 30 minutes. The contaminated water is then withdrawn back to Column $\mathrm{C}$ and collected into polybottles. If the rinse solution is discolored or thick, the washing process is repeated. Steam may then be used as a cleaning aid if laboratory analysis indicates that the concentration of the uranium in the rinse solution is less than 2000 or $4000 \mathrm{ppm}$ (depending on enrichment). Based on the current procedure, steam cleaning is allowed only after boric acid solution has been added to the cylinder.

The rinse sequence is repeated at least three times and continued until the uranium concentration of the solution is less than $500 \mathrm{ppm}$, as determined by the laboratory. After the final rinse, the cylinder is taken to the drying unit. Several changes to drying procedures have been implemented during the past two years. These changes were not examined in detail during the update of this report, as cylinder drying is a separate operational area [OA1.2.4] for evaluation.

\subsection{Input and Output Streams of Fissile Material}

The input stream of fissile material for large cylinder cleaning is the heel, which typically consists of $\mathrm{UF}_{6}$ and nonvolatile uranium compounds (e.g., $\mathrm{UO}_{2} \mathrm{~F}_{2}$ ). The heel is commonly assumed to be simply $\mathrm{UO}_{2} \mathrm{~F}_{2}$, since the $\mathrm{UF}_{6}$ should have sublimed during the withdrawal operations. In addition, this assumption is generally conservative from a criticality standpoint. Since $\mathrm{UO}_{2} \mathrm{~F}_{2}$ has a lower molecular weight than $\mathrm{UF}_{6}$, a given weight of heel will have more uranium atoms if it is considered to be $\mathrm{UO}_{2} \mathrm{~F}_{2}$. Furthermore, since the reaction of $\mathrm{UF}_{6}$ with water releases hydrogen (as $\mathrm{HF}$ ); the $\mathrm{H} / \mathrm{U}$ ratio will often result in a more reactive solution (neutronically) if a $\mathrm{UO}_{2} \mathrm{~F}_{2}$ heel is assumed.

The output streams of fissile material are the wash and rinse solutions, which are essentially a $\mathrm{UO}_{2} \mathrm{~F}_{2}-\mathrm{H}_{2} \mathrm{O}$ mixture. These solutions, as discussed above, are collected into polybottles. Except for the last rinse, the uranium concentration is normally above 500 ppm. Wash and rinse solutions are taken to the fluorides-complexing handtable [SS2.3] for eventual transfer to the recovery/blending handtable [SS2.4]. 
When this report was first prepared in 1992, an option existed for the disposition of the final rinse solution. Because it had a concentration below $500 \mathrm{ppm}$, this solution could be poured into the drain at the small cylinder rinse area for transfer to the overhead storage [SS4.5]. This option was not discussed in IP 1.2.4. During the last two years, a new drain system has been installed, and apparently rinse solutions with concentrations below $500 \mathrm{ppm}$ can again be pumped to overhead storage. A schematic of the input/output streams is shown in Figure 3.2.

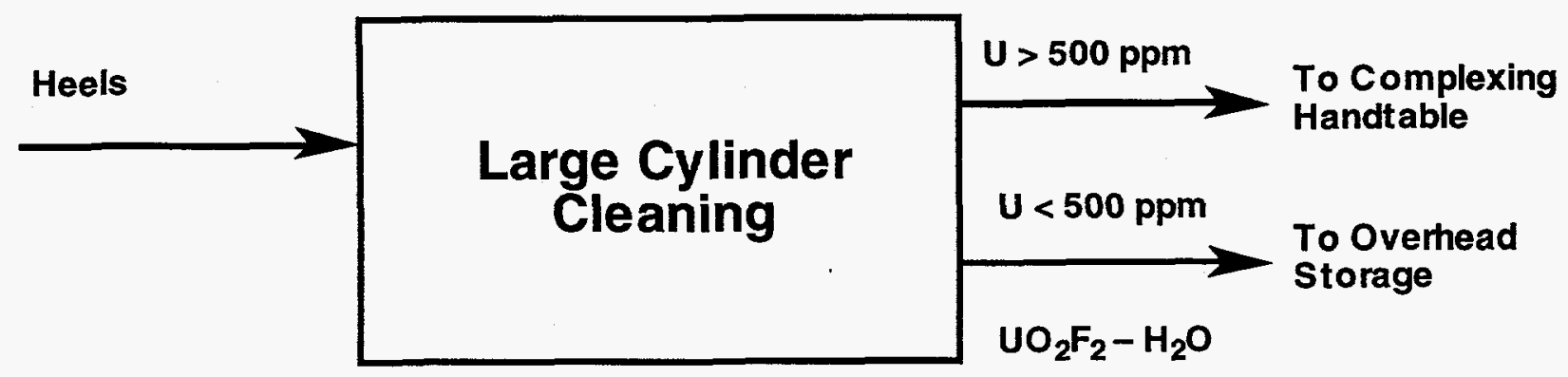

Figure 3.2 Schematic of input and output fissile streams for large cylinder cleaning operations 


\section{EXISTING PORTS DOCUMENTATION}

This section reviews existing PORTS documentation relevant to large cylinder cleaning operations. Section 4.1 examines current NCS documentation for cylinder cleaning in X-705, which includes the Final Safety Analysis Report (FSAR), Operational Safety Requirements (OSRs), development memos (DMs), field change agreements (FCAs), and operating procedures. (Ref. 1 provides background and discusses the historical development of these various types of documents.) Section 4.2 summarizes additional PORTS documents that pertain to facilities other than X-705 but have potential criticality impact on cylinder cleaning. Finally, several technical reports that examine cylinder operations in general are identified in Section 4.3.

\subsection{Documentation on Cylinder Cleaning in X-705}

Several current PORTS documents address the nuclear criticality safety of large cylinder cleaning operations in X-705:

-FSAR $^{3}$, Sections 4.3.1.3.2.1, 4.3.2.2.3 D(1-3), 5.3.1.2.1, and 5.3.2.2.1

-DM-868, Rev. $4^{4}$, pp. 29-31

-DM-868, Rev. 4, Add. $1^{5}$

$-\mathrm{FCA}-382^{6}$

-In-Hand Procedure (IP) RD 1.2.4, Rev. 4, Ch A-C (discussed in Section 3)

-OSR, GAT/GDP-1074, Part H, Rev. 37, Sections 5.3.2.3(1-3)

The FSAR section (4.3.1.3.2.1) describing large cylinder cleaning operations is rather outdated. A few significant differences between the procedures discussed in the FSAR and those presented in Section 3.1 of this report are worthwhile to highlight here. The basic heel weight and assay (enrichment) limits that determine whether a large cylinder can be cleaned without a specific Field Agreement have been modified several times in the past 10 years, and these changes were not incorporated into the 1990 update of the FSAR. Recent variations have also been implemented for the disposition of wash and rinse solutions, and the cylinder microfiltration unit is no longer used for this purpose. Finally, the use of threaded rods or hydrochloric acid to remove rust from the inside of the cylinder has also been discontinued.

Section 4.3.2.2.3 of the FSAR contains administrative controls identical to those in the OSR (Ref. 7). These controls, described in only general terms, are by no means complete: A consolidated listing of criticality administrative controls is developed in Section 5.3 of this report. Section 5.3.2.2.1 of the FSAR presents administrative controls and design features of the cylinder rinse microfiltration system, which is no longer used for cylinder solutions.

Section 5.3.1.2.1 of the FSAR lists three potential accident scenarios applicable to criticality of cylinders. A more-detailed review of the text reveals that the discussion applies primarily to smaller cylinders. Accidents with large cylinders are simply dismissed as being incredible because of the low assay of uranium. Section 6 of this report considers various accident scenarios involving large cylinder cleaning. 
DM-868 discusses two general topics relative to large cylinder cleaning-heel weight/assay limits and batching of recovered solutions (primarily into drums or large batch tanks). The limits for heel weight/assay have since been modified (first by Add. 1 and later by FCA-382). Cylinder solutions are generally not batched into drums or large tanks. As a result, DM-868 is no longer very applicable to current operations involving large cylinders. (A few, apparently minor, changes to DM-868, implemented in late 1994 and early 1995, were not evaluated as part of this report.)

On the other hand, a few topics mentioned in DM-868 do not appear in other documentation on large cylinders. First, the discussion in this DM seems to permit washing without boric acid solution if the enrichment is known to be $0.95 \%$ or less. (Another statement appears to require a safety factor of $0.1 \%$ enrichment, so that perhaps boric acid is needed if the enrichment exceeds $0.85 \%$.) Second, DM-868 also provides instructions on procedures to be followed if the heel mass/enrichment exceeds the safe limit-vaporization by heating should be used to reduce the heel, and if not successful, the cylinder should be cut open rather than cleaned.

Addendum 1 to DM-868 was apparently published to expedite cleaning of 10-ton (48in. diameter) cylinders because of a demanding operational requirement arising in 1986. These procedures were somewhat modified by FCA-382, which thus appears to supersede this addendum. FCA-382 provides maximum heel weights and maximum volumes of cleaning solutions (as a function of enrichment). These limits are consistent with those of the current cleaning procedure.

As discussed in Section 3 of this report, IP RD 1.2.4, Rev. 4, Ch A-C, is the current In-Hand Procedure for large cylinder cleaning operations. This is one of the newest InHand Procedures, having been initially approved in March 1992, with three "red-line" changes added in 1993.

In summary, most of the documentation related to criticality safety of large cylinder cleaning operations is old and outdated. Conflicting requirements are imposed, and confusion on currently allowed practices is apparent. The recent efforts to develop a Nuclear Criticality Safety Approval and Evaluation (NCSA/NCSE) should result in an up-to-date document that will enable these other documents to be superseded or rescinded. Revisions of top-level documentation, such as the Safety Analysis Report and Technical Specifications, are also in progress.

\subsection{Other PORTS Procedures for Large Cylinder Operations}

In addition to cleaning operations in X-705, large cylinders are used at the feed, withdrawal, and other areas of the cascade. As a result, at least two additional PORTS documents for these areas contain information that has potential impact on criticality safety of cylinder cleaning. As will be discussed in Section 5.1.2, the maximum enrichment of large cylinders used to transport $\mathrm{UF}_{6}$ is $5 \%$ (30-in. cylinders) and $4.5 \%$ (48-in. cylinders), assuming moderation control. For onsite use only, however, PORTS procedures define special situations in which these enrichments may be exceeded.

Operating Method CE 10.2.28 allows $\mathrm{UF}_{6}$ enrichments of $7.0 \%$ (for 30 -in. cylinders) and $5.25 \%$ (for 48 -in. cylinders) in the case of a disaster requiring maximum withdrawal from the cascade. Clearly this is a very unique situation. 
In addition, $\mathrm{FCA}-523^{9}$, which addresses withdrawal of $\mathrm{UF}_{6}$ into $48 \mathrm{X}$ (10-ton) cylinders, permits a $5.0 \%$ enrichment for onsite operations in order to reduce handling and sampling during filling. In practice, one $48 \mathrm{X}$ cylinder is first filled with $\mathrm{UF}_{6}$ blended to the desired enrichment, and this $48 \mathrm{X}$ is then used to fill four 30 -in. (2.5-ton) cylinders. During the fill of the $48 \mathrm{X}$ cylinder, the enrichment may be as high as $5.25 \%$. The FCA also requires that these cylinders be clearly identified. (They are now painted red.)

\subsection{POEF Reports on Large Cylinders}

In recent years, several POEF reports have addressed issues with large cylinder operations at PORTS. Although not specifically limited to cylinder cleaning, these reports contain useful information relevant to criticality analysis of cylinders.

Current enrichment limits for the contents of large cylinders are based on moderation control, i.e., the purity of the fill material is at least $99.5 \% \mathrm{UF}_{6}$. If moderation control is not implemented, only a $1 \%$ enrichment is permitted. POEF-T- 349510 analyzes the criticality safety issues pertaining to a potential loss of such moderation control.

POEF-T-356311 examines criticality issues of filling $48 \mathrm{X}$ cylinders with $\mathrm{UF}_{6}$ enriched to $5.0 \%$. This report provides the justification for procedures allowed under FCA-523, as was discussed above.

POEF-T-359712 analyses the feasibility of placing $10 \%$-enriched $\mathrm{UF}_{6}$ in 30 -in. (2.5 ton) cylinders. It addresses cylinder cleaning, filling, withdrawal, temporary storage, sampling, and transfer operations. A recent document, it contains an excellent reference list of other publications relevant to large cylinder operations. 


\section{CONTROL PARAMETERS, DESIGN FEATURES, ADMINISTRATIVE CONTROLS, AND SAFETY SYSTEMS}

This section assesses each of the control parameters applicable to the various stages of large cylinder cleaning operations. From this analysis, consolidated lists of design features, administrative controls, and safety systems are developed. Finally, the cleaning procedures used in X-705 are compared with those provided in Appendix B of ANSI N14.1 13 .

\subsection{Control Parameters}

\subsubsection{Geometry}

The only two items of hardware involved in large cylinder cleaning operations that do not meet the single-parameter geometry limits of ANSI/ANS $8.1^{14}(\sim 5$-in. diameter cylinder) are the $\mathrm{UF}_{6}$ cylinders themselves and the $\sim 50$-gal. tank for mixing the boric acid solution. (Although Columns $\mathrm{A}, \mathrm{B}$, and $\mathrm{C}$ are six inches in diameter, they are unreflected. Furthermore, as will be discussed in the next section, because of the enrichment they would be subcritical even if fully reflected.) The diameter of the $\mathrm{UF}_{6}$ cylinders is nominally either 30 inches or 48 inches, depending on the model and $\mathrm{UF}_{6}$ design weight, and therefore not geometrically favorable for enrichments greater than about $1 \%$. This geometry is an unavoidable condition that requires other controls.

The mixing tank is of similar unfavorable geometry but is also rather impracticable to change. Although boric acid could conceivably be mixed in a safe-size tank (e.g., 5-gal. containers), the increased operational effort would be substantial. Furthermore, the crystals must be thoroughly dissolved in the water for full effectiveness, and it is quite likely that using small containers could result in a less safe situation (improperly mixed solution). Section 6.2 will address the contingencies necessary to achieve a critical reaction in the mixing tank. An administrative control prohibits the use of Column A for contaminated solutions (restricts its use for clean boric acid solution only).

It should be noted in passing, however, that the mixing tank is always uncovered. Because it is located against the west wall of the building and not near the overhead storage, it is not clear that any credible scenario exists that could result in a uranium solution collecting in the tank. On the other hand, an uncovered, unfavorable-geometry container appears to be contrary to the general safety practices enforced throughout $\mathrm{X}$ 705 .

\subsubsection{Enrichment}

As noted above, the unfavorable geometry of large cylinders is an unavoidable condition that requires additional controls in cleaning operations. Enrichment is the toplevel control, from which other controls (i.e., mass and volume of solution) are subsequently derived.

The nuclear industry has devoted a substantial effort to standardize procedures for the transport of $\mathrm{UF}_{6}$ in large cylinders. These standards have been promulgated in ANSI N14. I and DOE/ORO-651 15 , and incorporated either directly or indirectly into various Department of Transportation regulations (49 CFR 17316), Nuclear Regulatory Commission regulations (certificates issued under 10 CFR 7117), and DOE Orders (certificates issued under DOE $1540.2^{18}$ and DOE 5480.319). 
In accordance. with the above documents, enrichment of $U_{6}$ is limited (under moderation control) to a maximum of $5.0 \%$ for 30 -in. cylinders and to $4.5 \%$ for 48 -in. cylinders used for transport. (Some models are limited to $1.0 \%$, which is the maximum for all large cylinders if moderation control is not implemented.) On the other hand, DOE/ORO-651 does permit enrichments up to $5 \%$ for $48 \mathrm{X}$ cylinders that are restricted to in-plant use. As noted in Section 4.2, FCA-523 permits this enrichment for 48X cylinders at PORTS (provided they are clearly marked), and PORTS Operating Method CE 10.2.2 allows $\mathrm{UF}_{6}$ enrichments of 7.0\% (for 30-in. cylinders) and $5.25 \%$ (for 48 -in. cylinders) in the case of a disaster requiring maximum withdrawal from the cascade.

Except for the few exceptions noted above, which should be readily discernible, the maximum enrichment of $\mathrm{UF}_{6}$ in large cylinders is $5 \%$ (4.5\% in 48-in. cylinders). Although IP RD 1.2.4 requires a Field Agreement for cleaning large cylinders if the enrichment exceeds 5\%, such a situation would almost never be expected to occur. On the other hand, IP RD 1.2.4 does not base its other controls solely on these maximum enrichments. Instead, both the allowed mass of heel and the amount of water that can be used in cleaning are determined from the "actual" enrichment of the cylinder contents. These procedures are discussed below and assessed from a criticality standpoint in Section 6.

\subsubsection{Mass}

Mass is one of the two principal control parameters for large cylinder cleaning, and IP $\mathrm{RD}$ 1.2.4 establishes several administrative controls based on heel weight. If the assay (enrichment) of the heel is greater than $4.5 \%$ but less than or equal to $5 \%$, the heel weight is restricted to 41 pounds. (The procedures do not clarify what should be done if the heel weight exceeds 41 pounds with this enrichment.) If the heel weight is less than or equal to 41 pounds (and the enrichment $\leq 5 \%$ ), the operator needs no further approval before proceeding with cylinder cleaning.

If the enrichment is $4.5 \%$ or less, cylinders with heels exceeding 41 pounds may be cleaned with concurrence of supervision, providing the requirements of Table 5-1, IP RD 1.2.4, are satisfied. (It is not clear what supervisory action is required to demonstrate concurrence.) For example, as shown in Table 5.1 below, a heel weight of 49 pounds is allowable if the enrichment is $4.5 \%$.

Table 5.1 Maximum heel weight limits from IP RD 1.2.4, Rev. 4, Ch. A-C

\begin{tabular}{|cc|}
\hline Assay $235 \mathbf{U}$ & Safe Heel Weight (lb.) \\
\hline $4.5 \%$ to $5 \%$ & 41 \\
$4 \%$ to $4.5 \%$ & 49 \\
$3 \%$ to $4 \%$ & 60 \\
$2 \%$ to $3 \%$ & 109 \\
$1 \%$ to $2 \%$ & 332 \\
Below $1 \%$ & 5000 \\
\hline
\end{tabular}


Although the explicit bases for the above limits on heel mass do not appear to be published in any PORTS documentation, they are consistent with safe mass limits from Figure A-2 of GAT $-225^{20}$, which has served as the criticality reference at PORTS for many years. This document defines a safe mass as approximately " $43 \%$ of the minimum critical mass for the assay involved." The limits in Table 5.1 are also consistent with those in more familiar criticality documents, such as TID-7016 21 and ANSI/ANS 8.1. For example, the subcritical mass limit of TID-7016 for 5\% enrichment is approximately $30 \mathrm{~kg}$ of uranium, which equates to approximately $85 \mathrm{lb}$. of $\mathrm{UO}_{2} \mathrm{~F}_{2}$. Consequently, 41 pound maximum heel includes a safety factor of more than 2 (in addition to the safety factor in TID-7016). For 4.5\% enrichment, the subcritical mass limit of TID-7016 is approximately $38 \mathrm{~kg}\left(\sim 108 \mathrm{lb}\right.$. $\left.\mathrm{UO}_{2} \mathrm{~F}_{2}\right)$. As before, 49 pounds represents a safety factor greater than 2 above the conservative TID-7016 value. Heel-weight limits for the other enrichments specified in Table 5.1 have a generally similar, or even larger, safety factor. (The 5000-1b. heel limit for enrichments $<1 \%$ represents an essentially full 30 -in. cylinder.)

Similar comparisons can be made with the limits for uniform aqueous solutions in ANSI/ANS 8.1. However, one needs to be cautious since the limits listed in this reference (e.g., Table 6) are not applicable to oversaturated solutions.

Three comments about the IP RD 1.2.4 heel-weight limits are worth noting. First, Table 5.1 is somewhat ambiguous for enrichments corresponding to the discontinuities in heel-weights (i.e., $4.5 \%, 4 \%, 3 \%$, and $2 \%$ ). Since $5 \%$ is an allowable enrichment for 30 in. cylinders, it appears as if the upper limit is intended to be inclusive. This is further supported by an outdated NCS warning sign posted at the large cylinder cleaning area which states that the maximum allowable heel for 10- and 14-ton cylinders is 49 pounds at $4.5 \%$. Second, the above procedures imply that the operator knows the correct enrichment. Concerns about this assumption are discussed in Section 6 which evaluates the Double Contingency Principle. Third, the above procedures also assume that the heel weight is accurate, or its error is no larger than the considerable safety factor. This assumption is also examined in Section 6.

\subsubsection{Volume of Cleaning Solution}

The volume of cleaning solution is the second principal control parameter for large cylinder cleaning. (Ironically, volume is not identified as a control in either the FSAR or OSRs.) Under usual conditions, the operator is allowed to add five gallons, or approximately 18.9 liters, of (borated) water to wash the cylinder. As with mass, the explicit basis for this volume limit does not appear to be documented. Figure A-4 of GAT-225 indicates that a safe volume for 5\%-enriched solution is about 7 gallons. This is consistent with the 25-liter (6.6-gal.) subcritical volume limit of TID-7016 for 5\%enriched $\mathrm{UO}_{2} \mathrm{~F}_{2}$. Likewise, the subcritical limit from ANSI/ANS 8.1 is 30.6 liters (8.1 gallons), but again this limit does not apply if the concentration of uranium is greater than a saturated solution. (These subcritical limits are also consistent with a more recent report ${ }^{22}$ prepared by MMES for LEU solutions.)

Two points of caution are in order. First, the subcritical limits discussed above do not account for double batching. Potential criticality concerns with double batching are discussed in Section 6. Second, these subcritical limits assume that the $\mathrm{UO}_{2} \mathrm{~F}_{2}$ solution is reflected by water. If the cylinder being cleaned contains a large heel mass, one can envision a situation in which a $\mathrm{UO}_{2} \mathrm{~F}_{2}-\mathrm{H}_{2} 0$ mixture is surrounded (at least partially) by a 
dry $\mathrm{UO}_{2} \mathrm{~F}_{2}$ or $\mathrm{UF}_{6}$ reflector. An overall volume limit is a rather meaningless parameter because the volume of fissile material could exceed the 5-gal. limit even before cleaning solution is added. (In fact, this entire concept of control by volume of cleaning solution is really just another way of describing moderation control.) As mentioned in Section 4.3, POEF-T-3495 examines criticality issues associated with loss of moderation control. In a very idealized situation, this report indicates that the addition of only five gallons of water to a full cylinder ( $5 \%$ enrichment) can result in a critical configuration. Although achieving these idealized conditions (spherical solution, optimum $H / U$, maximum theoretical density of UF6 reflector) may not be very credible, these calculations do show how little margin may exist, even when only five gallons of water is added to a full cylinder. (On the other hand, the assumption that the heel is a water-reflected sphere may be overly conservative for realistic cleaning situations.) Concerns with using volume of solution as a control parameter are discussed in more detail in Section 6.

Table 8-1 of IP RD 1.2.4, shown as Table 5.2 of this report, allows the operator to add as many as 200 gallons of cleaning solution if the heel weight is less than 41 pounds and the specified enrichment criteria are satisfied. From a practical standpoint, 200 gallons is not very realistic. Since the solution must be added and withdrawn in 5-gal. increments, and since all contaminated solution must generally be processed through uranium recovery [S2.0], a strong incentive exists to minimize the volume of solution used.

\subsubsection{Neutron Absorption}

The guidelines are confusing as to whether the use of neutron absorbers is a control parameter for cylinder cleaning. IP RD 1.2 .4 specifies that 0.5 pounds of boric acid crystals, $\mathrm{H}_{3} \mathrm{BO}_{3}$, will be added per gallon of wash solution in the mixing tank and that at least three washes will be completed using this solution. The OSRs for X-705 identify its use as a control, and hence an OSR stamp appears in the IP (Step 5.1.9). Nevertheless, for reasons discussed below, PORTS NCS personnel do not designate the use of boric acid solution as a principal control. (It is sometimes referred to as a tertiary control or protection in depth, in addition to the mass and volume controls discussed above.)

Table 5.2 Maximum cleaning solution for heel weights less than $41 \mathrm{lb}$.

\begin{tabular}{|cc|}
\hline Assay $235 \mathrm{U} \%$ & Cleaning Solution (gal.) \\
\hline Less than 0.95 & 200 \\
0.95 to 1.00 & 100 \\
1.00 to 1.25 & 80 \\
1.25 to 1.50 & 45 \\
1.50 to 1.75 & 30 \\
1.75 to 2.00 & 25 \\
2.00 to 2.50 & 15 \\
2.50 to 3.00 & 10 \\
3.00 to 5.00 & 5 \\
\hline
\end{tabular}


Criticality control by soluble neutron poisons is generally avoided in criticality safety because of the detailed administrative controls needed to assure their initial presence and the inherent danger that they could be precipitated out of solution by a single event. When used, these poisons are almost never the primary control. Probably because of their infrequent use, no ANSI standard is yet devoted to their application, unlike borosilicate-glass raschig rings, which are the subject of ANSI/ANS 8.523. Concerning neutron absorbers, ANSI/ANS 8.1 simply states that:

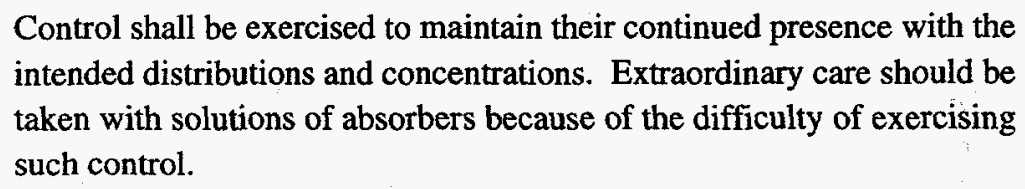

Interpretation of this Standard implies that three criteria must be satisfied if the boric acid is to be considered a bona fide control: (1) the presence of the boron at the specified concentration must be verified, (2) the specified isotopic composition of the boron must be assured, and (3) events causing precipitation of the boron must be prevented. For large cylinder cleaning operations in X-705, issues can be identified for each of these criteria.

First; with current procedures it is doubtful that the inadvertent omission of boric acid crystals from the wash solution would be detected. No record is maintained to document the preparation of boric acid solution. With apparently little or no supervision, the operator is alone responsible for adding the correct amount of boric acid to the mixing tank.

Second, the natural isotopic composition of boron varies more than that of most elements, and a demand exists for boron enriched in the isotope ${ }^{10} \mathrm{~B}$. This latter fact would imply that there is an inventory of depleted boron available for any market that does not require the ${ }^{10} \mathrm{~B}$ isotope. In 1993, the PORTS NCS staff obtained a letter from US Borax indicating they did not alter the natural composition of their borate products. Nevertheless, current procurement and operating procedures are insufficient to verify the supplier or changes in specifications for the boric acid.

Third, the most troublesome issue associated with the use of soluble poisons is generally the possibility of precipitation of the poison from the solution. When boric acid solution is added to a large cylinder, a chemical reaction can occur between the water and uranium products. The degree of precipitation or separation of the boron from the uranium solution has been identified by PORTS and other MMES NCS personnel as an issue that needs to be resolved before boron can be considered an effective control.

Even though the use of boric acid solution is not considered as a principal control, it certainly adds some safety to large cylinder cleaning operations. These considerations will be discussed in Section 6 .

\subsubsection{Concentration}

As explained in Section 5.1.4, the volume of cleaning solution is generally limited to five gallons, unless certain heel weight and enrichment restrictions are satisfied. The use of steam is not allowed in the early stages of the cleaning process because of the increase in solution volume resulting from the condensation of the steam. After a rinse solution has been analyzed and shown to have a uranium concentration less than 2000 to 4000 ppm (depending on enrichment), steam may be used as a cleaning agent provided five 
gallons of borated water are first added to the cylinder. This appears to be a very conservative concentration limit. The subcritical limit of ANSI 8.1 is $261 \mathrm{~g} / 1(261,000$ $\mathrm{ppm}$ ) for a $5 \%$-enriched $\mathrm{UO}_{2} \mathrm{~F}_{2}$ solution. It should be noted, however, that the concentration of the solution following the use of steam often increases somewhat because of the cleaning benefit of the steam itself. However, since the concentration requirements are so far below the subcritical limit, and because the steam generally adds only a small increase in solution volume, the steam cleaning procedures appear very safe.

It is probably worthwhile to review in detail the sequence of events for using steam, specified in IP RD 1.2.4. These procedures appear to require that steam cannot be used until at least one rinse has been performed. This implies that the normal wash process (perhaps $\sim 10$ washes) is complete. If the use of steam is considered necessary, it must be used with borated water. Once the steam use is complete, it would appear also that at least three more rinses are then required. Although the wording of IP RD 1.2.4 allows room for interpretation, it does not appear to permit steam at any time during the initial wash process or without the use of borated water.

Concentration limits are also invoked for disposition of the contaminated solutions at the end of the cleaning operation. Solutions with greater than $500 \mathrm{ppm}$ are taken to the fluorides-complexing handtable as the first step in the recovery process. Solutions with less than $500 \mathrm{ppm}$ may be poured into a drain and pumped to the overhead storage. However, since generally only the final rinse meets this criterion, all solutions from large cylinder cleaning are often merely sent to the handtable.

\subsubsection{Interaction}

The uranium-bearing containers in the vicinity of the large cylinder cleaning area include the cylinder being cleaned, other cylinders awaiting cleaning, Column $C$ (and perhaps Column B), an occasional sample bottle, and the polybottles on the multiposition cart. Since the cart is used in many operations in X-705, this report does not address the interaction with polybottles. The effect of the interaction with the other containers appears very small, but no calculations have been performed.

Two turning fixtures are available in the large cylinder cleaning area. Although IP $\mathrm{RD}$ 1.2.4 (I5.1.6) leaves room for interpretation of required procedures, in practice only one cylinder is cleaned at a time. The IP, however, does permit as many as eight large cylinders to be in X-705. Although the interaction of these cylinders (dry, low-mass heels) is considered small, the presence of eight cylinders increases the likelihood that one cylinder could be confused with another. This subject will be addressed in more detail in Section 6.

\subsubsection{Moderation}

With the exception of the cleaning solution (which is considered a volume control), moderation is only indirectly applicable to the cleaning operations themselves. As discussed in Section 5.1.2, enrichments exceeding $1 \%$ are permitted in large cylinders only under moderation control. As a result, there is an implicit assumption that cylinders to be cleaned do not contain a significant quantity of water (which could invalidate the volume restrictions explained in Section 5.1.4). On the other hand, if this assumption were not satisfied, it is quite possible that a criticality scenario could develop prior to the cylinder's delivery to $\mathrm{X}-705$. 


\subsubsection{Reflection}

This control is not applicable to large cylinder cleaning. No restrictions are imposed, and none appear necessary, on limiting the reflection of the cylinder itself or the mixing tank. As noted before, the other geometries are favorable even if fully reflected (for $5 \%$ enrichment).

\subsection{Design Features}

With the exception of the design of the polybottle cart, the only design feature relevant to large cylinder cleaning operations appears to be the vertical columns. Based on an expected maximum enrichment of $5 \%$, these columns are approximately 6 inches in diameter (and unreflected). In addition, Column B, which is used for venting cylinders with a cold pressure above atmospheric, contains raschig rings.

The OSR does not designate the diameter of these cylinders (or their lack of reflection) as a design feature for criticality safety.

\subsection{Administrative Controls}

Based on the discussion in Section 5.1, a consolidated listing of administrative controls applicable to large cylinder cleaning operations is presented in Table 5.3.

The determination of what constitutes, or does not constitute, an administrative control is often rather subjective. Some procedures are clearly administrative controls, e.g., "Do not clean any cylinder containing an assay greater than $5 \%$ without a NCS Field Agreement," while other procedures are merely one of several safe ways to accomplish a given task. (Ironically, the above quote-IP RD 1.2.4, $\mathbb{1 5 . 1 . 2 - i s ~ n o t ~ i d e n t i f i e d ~ i n ~ t h e ~}$ OSR as an administrative control.) Because of the administrative consequences (occurrence reports, etc.) of violating an administrative control, care must be taken to distinguish actual safety procedures from merely safe procedures.

The administrative controls of Table 5.3 were developed independently from those listed in GDP-1074. OSRs designated in GDP-1074 are also identified by an "OSR stamp" in IP RD 1.2.4. A comparison of similarities and differences between Table 5.3 and GDP-1074 is informative. 
Table 5.3 Administrative controls for large cylinder cleaning

\begin{tabular}{|c|c|}
\hline Parameter & Administrative Control \\
\hline Geometry & $\begin{array}{l}\text { Column A not to be used for contaminated solutions (to avoid possible } \\
\text { backflow into mixing tank) }\end{array}$ \\
\hline Enrichment & Field Agreement required if enrichment $>5 \%$ \\
\hline Mass & $\begin{array}{l}\text { Field Agreement required if heel weights exceed specified limit (based on } \\
\text { enrichment) }\end{array}$ \\
\hline Volume & $\begin{array}{l}\text { Only five gallons of cleaning solution used unless enrichment limits satisfied } \\
\text { and heel weight }<41 \mathrm{lb} \text {. }\end{array}$ \\
\hline Neutron Absorption & $\begin{array}{l}\text { Boric acid solution }(10 \mathrm{~g} / 1) \text { required for at least } 3 \text { wash solutions and until } \\
U<1000 \mathrm{ppm}\end{array}$ \\
\hline Concentration & $\begin{array}{l}\text { Steam used only if rinse solution tests low in ppm } U \text { (based on enrichment) } \\
\text { Solutions above } 500 \mathrm{ppm} U \text { processed through recovery* } \\
\text { Only solutions less than } 500 \mathrm{ppm} U \text { may be processed through overhead } \\
\text { storage* }\end{array}$ \\
\hline \multirow[t]{2}{*}{ Interaction } & Polybottles stored/transported on multi-position cart* \\
\hline & Only one cylinder cleaned at a time \\
\hline Moderation & Enrichments $>1 \%$ originally under moderation control* \\
\hline Reflection & None \\
\hline
\end{tabular}

First, some of the controls in Table 5.3 are so universal that they would not be expected to be specified in GDP-1074. For example, moderation control for cylinders with greater than $1 \%$ enrichment is applicable throughout the $U^{-} F_{6}$ community, and its absence from GDP-1074 is not surprising. Other controls in Table 5.3, such as the interaction limitations on polybottles, are also very general and not unique to large cylinder cleaning. It could be argued that they are covered by similarly general comments in Section 2.10 (General), 4.0 (Design Features), and 4.1 (System Geometry) of GDP-1074.

On the other hand, some of the administrative controls identified in Table 5.3 appear to be inexplicably absent from GDP-1074. As mentioned above, the requirement for a Field Agreement if the enrichment exceeds $5 \%$ is one example. Also omitted are the volume and concentration controls of Table 5.3. While it could be argued that the concentration controls are too new to be included, the absence of the volume controls is particularly disturbing. (Volume controls have been in existence since at least early 1985, when Addendum 1 to DM-868, Rev. 4, was published.) Since these procedures are not identified at all in the Operational Safety Requirements, they are not designated by the OSR stamp in IP RD 1.2.4, and operational personnel are not alerted to their safety importance. Perhaps not coincidentally, operational personnel voiced some disfavor with the restrictions on volume and concentration imposed by the IP. 
The requirement to clean only one cylinder at a time is also not listed as an administrative control. The evaluation of criticality issues concerning the cleaning of two cylinders simultaneously was not addressed during preparation of this report.

\subsection{Safety Systems}

As in the case of administrative controls, safety systems can also be somewhat subjective to define. Although no equipment or hardware in X-705 appears to qualify as a safety system for large cylinder cleaning, any scale used to determine heel weight appears to meet such qualifications. Because the mass of the heels is used as an administrative control, a significant error in heel weight has a major impact on criticality safety.

Considerable attention is devoted to scales for both economic and materialaccountability reasons ${ }^{24}$. Whether their role in the safety of cylinder cleaning operations is appreciated is not clear, but the PORTS NCS staff was informed of a recent proposed change to modify certain scale control limits. Because the scales are not physically in X705 , they are not listed as a safety system in GDP-1074, Part H. It is not clear if they are so designated in other documentation (for either cylinder cleaning or other reasons). The concern over accuracy of heel weight will be discussed further in the Double Contingency Analysis of Section 6 and Recommendations for Further Consideration in Section 7.

\subsection{Comparison with Cleaning Procedures of ANSI N14.1}

Appendix B, ANSI N14.1, contains an example procedure for the cleaning of large cylinders. It is important to note that because this procedure is an appendix, it is formally not part of the Standard and therefore does not imply requirements, recommendations, or restrictions. In fact, the inclusion of procedures in this appendix does not even imply that a consensus has been reached on their safety. Nevertheless, a comparison of this procedure with IP RD 1.2.4 is instructive. Table 5.4 summarizes the key areas of large cylinder cleaning operations in order to emphasize the similarities and differences of these two procedures.

Before discussing these issues in detail, an overall summary of the control philosophy of the two procedures is highlighted. As described in Section 5.1, the procedures of IP RD 1.2.4 use mass and volume as the two principal control parameters. Boron is sometimes considered a tertiary control, but formally has no status as discussed above. The procedures of ANSI N14.1, Appendix B, are significantly different. Although mass is used as one of the control parameters, neutron absorption is the second. (Of course, volume is the second control when only five gallons of unborated water is used.) This dissimilarity has a major effect on the details of the two procedures. 
Table 5.4 Comparison of procedures of ANSI N14.1 Appendix B and IP RD 1.2.4

\begin{tabular}{|c|c|c|}
\hline Issue & ANSI N14.1 Appendix B & PORTS IP RD 1.2.4, Rev. 4, Ch. A-C \\
\hline $\begin{array}{l}\text { Enrichment } \\
\text { Limit }\end{array}$ & $5 \%$ & $5 \%$ \\
\hline \multirow[t]{2}{*}{ Heel Weight } & Checkweigh cylinder prior to cleaning & Read weight from DYMCAS printout \\
\hline & $\begin{array}{l}\text { Basic limit } 25 \mathrm{lb} \text {. (30-in.), } 50 \mathrm{lb} \text {.(48-in.) } \\
\text { without additional restrictions }\end{array}$ & $\begin{array}{l}\text { Basic limit } 41 \mathrm{lb} \text {. without additional } \\
\text { restrictions }\end{array}$ \\
\hline \multirow[t]{2}{*}{ Boron } & Concentration $10 \mathrm{~g} / 1$ & Concentration $10 \mathrm{~g} / 1$ \\
\hline & Content certified by laboratory & Content not certified \\
\hline \multirow[t]{8}{*}{ Wash } & $\begin{array}{l}\text { 5-gal unborated water when heel limits } \\
\text { satisfied }\end{array}$ & 5-gal borated water when heel limits satisfied \\
\hline & Additional water allowed, must be borated & $\begin{array}{l}\text { Additional water sometimes allowed (depends } \\
\text { on enrichment), must be borated }\end{array}$ \\
\hline & $\begin{array}{l}\text { Borated water required if heel limits } \\
\text { exceeded (unless enrichment }<1 \% \text { ) }\end{array}$ & Borated water always required \\
\hline & $\begin{array}{l}\text { Siphon solution from cylinder into } 1 \text {-gal. } \\
\text { container, then transfer to polybottle }\end{array}$ & $\begin{array}{l}\text { Vacuum draw solution from cylinder to } \\
\text { Column } C \text {, then transfer to polybottle }\end{array}$ \\
\hline & $\begin{array}{l}\text { If no solution can be siphoned, add } 5 \text { gal. } \\
\text { borated water }\end{array}$ & Not addressed \\
\hline & Wash time -10 minutes & Wash time -30 to 45 minutes \\
\hline & At least 3 washes required & At least 3 washes required \\
\hline & $\begin{array}{l}\text { Washes repeated until U concentration } \\
<5000 \mathrm{ppm}\end{array}$ & $\begin{array}{l}\text { Washes repeated until } U \text { concentration } \\
<1000 \text { ppm }\end{array}$ \\
\hline \multirow[t]{4}{*}{ Rinse } & $\begin{array}{l}\text { Use boroscope to check for uranium- } \\
\text { bearing compounds }\end{array}$ & Not addressed \\
\hline & Steam clean interior for 2 to 3 hours & $\begin{array}{l}\text { Minimum of } 3 \text { rinses, until } U \text { concentration } \\
<500 \text { ppm. Steam allowed after first rinse if } U \\
\text { concentration }<2,000-4,000 \mathrm{ppm} \text { (depends on } \\
\text { enrichment) but only with addition of five } \\
\text { gallons of borated water }\end{array}$ \\
\hline & $\begin{array}{l}\text { Use boroscope to assure cylinder } \\
\text { completely cleaned }\end{array}$ & Not addressed \\
\hline & $\begin{array}{l}\text { If oil present, add } 2 \text { gal. Freon or TCE, then } \\
\text { steam clean for } 10-20 \text { minutes }\end{array}$ & Not addressed \\
\hline
\end{tabular}


Essentially no differences exist in enrichment limits. When the procedures for cleaning both 30-in.- and 48-in.-diameter cylinders were consolidated into IP RD 1.2.4, all large cylinders were assumed to be capable of 5\% enrichment. As noted earlier, some older documentation (e.g., DM-868) still considers 48-in. cylinders to be limited to $4.5 \%$.

Two differences are noted in the requirements for the heel weights. The ANSI procedures specify that the cylinders should be check-weighed to verify the heel, while IP RD 1.2.4 relies on the weight from the DYMCAS printout. The reliance on records for determining heel weight raises several significant concerns addressed in Section 6 . The maximum heel weights of 25 pounds ( 30 -in.) and 50 pounds (48-in.) in the ANSI Appendix are probably based on limits imposed by transportation regulations. (Cylinders below these heel weights can be transported without overpacks.) On the other hand, as discussed in Section 5.1.3, the heel weight requirements of IP RD 1.2.4 are based on the subcritical mass limits at a given enrichment, with an additional $(\sim 2 \mathrm{X})$ safety factor.

The procedures for boron are significantly different. Although both documents specify a concentration of $10 \mathrm{~g} / 1$, those in the ANSI Appendix indicate that the content of the boron (presumably both concentration and isotopic composition) should be verified. As a result, boron is considered a safety control, and the volume restrictions are relaxed considerably. (The resolution of possible precipitation is not clear.) In IP RD 1.2.4, the boron content is not verified, and the second control is the volume of cleaning solution.

The majority of differences in washing procedures can be attributed to the verification of the boron content. Note that the ANSI Appendix does not specify boron unless the volume of wash solution is larger than five gallons. This is consistent with the discussion of volume controls in Section 5.1.4, but avoids the issue of accidental double batching. If the volume of wash solution exceeds five gallons, boron is used as the second control (mass is the first). In contrast, IP RD 1.2.4 allows more than five gallons only if the enrichment is not more than $3 \%$ (enrichment is then very much a part of the volume control). As noted earlier, the enrichment of a large cylinder should rarely be expected to exceed $5 \%$. Relying on the enrichment to be no more than that on the DYMCAS printout (or what the operator believes is on the printout) is addressed in Section 6.

Another important aspect of boron control, rather than volume control, is highlighted by the situation in which five-gallons of solution is added, but none (or very little) can be withdrawn. The cause of such a problem could be an unusual amount of impurities (e.g., corrosion products) or an unexpectedly large heel weight (i.e., the heel weight was incorrect). Using the ANSI procedures, another five gallons or more of (borated) water is added until the solution is dilute enough to flow. With the IP RD 1.2.4 procedures, the situation is not so simple and, in fact, is not addressed in the IP. If the heel weight actually were large (and the enrichment $\sim 5 \%$ ), the addition of more water (with uncertified boron) could very likely create a critical reaction. Depending on the exact circumstances, several alternatives may be possible, but such a choice should not be decided without careful consideration.

The wash procedures of the ANSI Appendix also specify the siphoning of the solution from the cylinder into a one-gallon container, instead of using an air-jet to transfer five gallons into a clear glass column as in IP RD 1.2.4. The rationale for the ANSI procedure is not clear. As will be discussed in the next section, this aspect of large cylinder cleaning in X-705 appears quite safe. The use of one-gallon containers would increase 
the operational effort significantly, and because of the higher possibility for spills, may be less safe than the methods used in X-705.

The final major difference between these two procedures is the rinsing process. The ANSI procedures call for steam cleaning for 2 to 3 hours; IP RD 1.2.4 requires at least three rinses, performed in a manner very similar to the washes (without the boron). Because the $\mathrm{UF}_{6}$ is always accompanied by at least small amounts of hydrofluoric acid (HF), the corrosion on the inside of the cylinder walls can be substantial. IP RD 1.2.4 does allow for steam cleaning after the first rinse, but five gallons of borated water must first be added to the cylinder. The ANSI procedures also call for examination of the inside of the cylinder using a boroscope, while the PORTS procedures do not. As a point in passing, in January 1993, PORTS utilized a system in which a video device could be inserted into a full large cylinder. The current status of such equipment is unknown, but it has apparently never been employed in cylinder cleaning operations. 


\title{
6. DOUBLE CONTINGENCY ANALYSIS
}

\subsection{General}

ANSI/ANS 8.1 addresses the Double Contingency Principle by stating:

Process designs should, in general, incorporate sufficient factors of safety to require at least two unlikely, independent, and concurrent changes in process conditions before a criticality accident is possible.

The text in both DOE $5480.5^{25}$ and $5480.24^{26}$ strengthens this recommendation by using the word "shall," so that the Double Contingency Principle is a requirement for DOE facilities. This requirement has been applicable to DOE facilities for many years.

The two key words of this principle-unlikely and independent-are not defined in any standard or DOE order. As a result, an evaluation of the Double Contingency Principle is a rather subjective assessment. The major points of contention are usually whether an event is truly unlikely or just off-normal, and whether an event is really incredible or just very unlikely. To a lesser extent, the criteria for independence can also be debated.

Before discussing specific situations, the likelihood of simple human error should be addressed. Although the assessment of a given error must be tempered with reason based on the situation, simple human error is often not considered to be unlikely (at least in the context of the Double Contingency Principle). Typical events that can be categorized as simple human error include misreading a data entry, recording an incorrect data entry, double batching materials, failing to follow a routine procedure, improperly opening or closing a valve, miscalculating simple arithmetic expressions, etc.

Obviously, no analysis can consider all potential events, and in all probability the ones never considered (thought of) will be the ones that cause a criticality accident. It is important, therefore, to establish safety controls that are robust against errors.

\subsection{Geometry Control}

Geometry control is the preferred top-level criticality control. It is generally straightforward to assess and very robust against changes and errors. ANSV/ANS 8.1 indicates:

\begin{abstract}
Where practicable, reliance should be placed on equipment design in which dimensions are limited rather than on administrative controls. Full advantage may be taken of any nuclear characteristics of the process materials and equipment. All dimensions and nuclear properties on which reliance is placed shall be verified prior to beginning operations, and control shall be exercised to maintain them.
\end{abstract}

Again, DOE orders add even more restrictive wording, so that geometry control is essentially required where possible.

Section 5.1 analyzed the control parameters for large cylinder cleaning operations. It was explained that all aspects of large cylinder cleaning are geometrically favorable except for the mixing tank for boric acid solution and the cylinder itself. None of this geometrically favorable equipment appears susceptible to expansion or other changes that 
would increase its size by any significant amount. Furthermore, any leak, spill, rupture, or overflow would generally flow to another favorable geometry (usually the floor).

Consequently, the one concern over unfavorable geometry (except for the cylinder itself) is the possible transfer of contaminated solution into the mixing tank. This event is discussed in current NCS documentation, and an administrative control has been established to preclude contaminated solution from being present in Column $A$, the column closest to the mixing tank, as shown in Figure 3.1. Using Column A only for clean boric acid solution is a good practice, but with the current piping arrangement, the transfer of solution to the mixing tank does not appear to be significantly more likely from Column A than from Column C. Nevertheless, through very negligent human error, an inattentive operator could connect a hose to a column containing uranium solution, place the other end in the mixing tank, and open the valves to enable gravity flow.

Even if solution were somehow transferred to the mixing tank, however, the solution would need to contain a critical mass of uranium for a criticality accident to occur. This would imply that the cylinder initially contained a very large heel (greater than the 85 pounds discussed in Section 5.1.3), that a criticality accident did not occur during the washing cycle, and that this large mass of uranium was transferred to the vertical column. Since the vertical column has a volume of only $\sim 8$ gallons and normally contains only five gallons, the solution in the column would likely be oversaturated, and siphoning such a solution from the cylinder would be difficult. Furthermore, the water in the mixing tank should contain boric acid. If a uranium-bearing solution were transferred to this tank, the boron (if present) would significantly reduce the reactivity of the resulting mixture.

The negligent action needed to transfer uranium-bearing solution to the boric acid mixing tank is considered to be an unlikely event. In addition, the combination of circumstances necessary to have such transfer contain a critical mass of uranium is at least one other unlikely event. As a result, even though the mixing tank is an unfavorable geometry, the Double Contingency Principle is satisfied.

\subsection{Other Controls}

Since the cylinders themselves are not geometrically favorable for most enrichments, controls are established for both mass of heel and volume of cleaning solution. (Both these controls are based, however, on the enrichment of the cylinder contents.) In order for a criticality accident to be possible and violate the Double Contingency Principle, one of the following general scenarios must occur:

Case 1: Both the mass and volume controls fail with events that are not unlikely

Case 2: Either the mass or the volume control fails with an unlikely event, and the other fails with an event that is not unlikely

Case 3: Both mass and volume controls fail with a single credible event (commonmode failure).

In addition, the most likely situation for a criticality accident is during the wash cycle, probably the first wash when the cylinder contains its full heel. Because the wash solution should contain boric acid, the conditions for Cases 1 through 3 above also need to be accompanied by a failure in soluble poisoning. As noted earlier, this could result from failure to add boric acid to the mixing tank, the use of depleted boric acid, or the precipitation of the boron from the solution. In the discussion that follows, the effect of 
the boric acid is conservatively ignored, since current procedures are not sufficient to qualify it as a control parameter. The control provided by the boron is a major uncertainty in the criticality analysis of large cylinder cleaning.

\subsubsection{General Loss of Mass or Volume Control}

Many scenarios were examined in order to find combinations of events that satisfy the above criteria (and hence violate the Double Contingency Principle). Before evaluating specific situations, however, it is worthwhile to examine in general how the mass and/or volume controls might be violated. Table 6.1 indicates various general events that could result in loss of mass or volume control. Because mass and volume controls are based on enrichment; loss of enrichment control can itself result in loss of either mass or volume control as well. For example, if an operator mistakenly believes that a cylinder contains an enrichment below $4.5 \%$, he is allowed (with concurrence of supervision) to clean it even though the heel weight is greater than 41 pounds. Likewise, if the heel weight is less than 41 pounds, a mistaken enrichment can permit the operator to use greater than five gallons of wash solution.

Several examples of actual situations that have occurred in cylinder cleaning operations at PORTS support the credibility of events listed in Table 6.1. During collection of data for this report, cylinder cleaning records from approximately 18 months of operation were examined. Many of these records indicated a negative heel mass-one record showed a heel of negative 41 pounds. The cleaning forms for these cylinders revealed that uranium compounds were removed during cleaning operations, so that the cylinders were by no means really empty. No attempts were made during the cleaning to reconstruct the actual heel weights in order to quantify the errors more accurately.

Table 6.1 Credible Events Resulting in Loss of Enrichment, Mass, or Volume Control during Large Cylinder Cleaning

\begin{tabular}{|lll|}
\hline Loss of Enrichment Control & Loss of Mass Control & Loss of Volume Control \\
\hline Error in DYMCAS records & $\begin{array}{l}\text { Scale weight incorrectly entered } \\
\text { in DYMCAS data base }\end{array}$ & Operator error/double batching \\
Misreading DYMCAS records & $\begin{array}{l}\text { Empty cylinder weight } \\
\text { incorrectly entered in DYMCAS } \\
\text { data base }\end{array}$ & $\begin{array}{l}\text { Solution is not completely } \\
\text { withdrawn before additional } \\
\text { solution added }\end{array}$ \\
$\begin{array}{l}\text { Improperly recording enrichment } \\
\text { on cylinder cleaning form }\end{array}$ & $\begin{array}{l}\text { DYMCAS weights incorrectly } \\
\text { read by operator }\end{array}$ & $\begin{array}{l}\text { Loss of mass control allows } \\
\text { operator to add more than 5 gal. }\end{array}$ \\
& $\begin{array}{l}\text { Cylinder confused with another } \\
\text { Loss of enrichment control }\end{array}$ & $\begin{array}{l}\text { Cylinder confused with another } \\
\text { Loss of enrichment control }\end{array}$ \\
\hline
\end{tabular}

In May 1993, a 10-ton cylinder (\#4A001118) with a heel weight of 39 pounds and $3.313 \%$ enrichment was placed on the cleaning fixture in X-705. After a wash cycle using five gallons of boric acid solution, no solution could be withdrawn from the cylinder. Working with the NCS staff, the operations personnel added another 15 gallons (incrementally), and the solution was eventually withdrawn. To date, that cylinder has been washed approximately 50 times. It has a current heel weight of about negative 35 pounds, and still is not clean. A sample of solution analyzed in June 1993 indicated an 
enrichment of $2.4 \%$. Consequently, the records on this cylinder were in error by at least 35 pounds in heel weight and about $1 \%$ (absolute) in enrichment. From a criticality standpoint, the fact that the enrichment error was below the value in the DYMCAS records was probably fortunate.

Finally, a similar situation occurred with another cylinder (\#4A001106) in September 1994. Although the heel weight was believed to be only 15 pounds (at $4.39 \%$ enrichment), only a very small amount of wash solution ( $\sim 2$ liters) could be removed from the cylinder. The follow-on developments of this event are unknown.

Although several possibilities exist for explaining such large heel-weight errors, no definitive causes have been attributed to the cases discussed above. In addition to potential human errors, it has been hypothesized that corrosion of the outer cylinder surface could result in significant mass reduction, leading to an underestimate in heel weight. Cylinders are required to be re-weighed after hydrostatic testing to establish a new empty weight. Even though the nominal time for such testing is every five years, cylinders do not need to be emptied just to perform a test, and consequently some cylinders have periods of 20 years or so between establishment of an updated empty weight. Another possibility for large heel weight errors is a failure to update the data base records or cylinder data plate after a hydrotest. In this case, both exterior and interior corrosion would contribute to error in heel weight.

Confusion of one cylinder with another is also an error of significant concern since it can result in both mass and volume controls (as well as enrichment) being lost by a single event. At least three instances of cylinder confusion are known to have happened in the past few years. As noted earlier, eight large cylinders may be in X-705 at the same time. In one instance, several wash cycles were completed on a cylinder before it was realized that the cylinder had been cleaned the day before. In another, the cylinder discussed earlier (\#4A001118) was taken off the stand when solution could not be withdrawn, and an operator mistook this cylinder for one awaiting hydrostatic testing. Fortunately, the error was noted before the cylinder was filled with ordinary water for the pressure test. Finally, in one paragraph of a memo discussing problems with cylinders \#4A001118 and \#4A001106, the serial number of the former was referenced, when the discussion actually pertained to the latter.

A further general concern over loss of cylinder cleaning controls is double batching. Double batching is typically not considered an unlikely event, and control parameters are often established at no more than half of their safe value in order to be robust against such an error. (As noted in Section 5.1.3, the mass control for cylinder cleaning contains this safety factor, as do most limits in effect for X-705.) Several scenarios for double batching appear quite plausible. One situation is simply an inattentive operator. During the examination of completed cleaning forms discussed earlier, it was noted that the attention to detail on these forms was often lax, and data were incompletely entered. It appears quite possible that the addition of wash solution would not be entered on the cleaning form immediately after that step of the procedure is completed, and confusion could result. If such an omission occurred at a change in shifts, the possibility for double batching would be even more likely. 


\subsubsection{Specific Examples Lacking Double Contingency}

Having discussed loss of criticality control in general, a few specific examples in which the Double Contingency Principal is not satisfied will be highlighted. It should be noted, as discussed above, that boron is not considered as a control.

Example \#1: Two Cylinders Confused: In this scenario, two cylinders have been delivered to X-705. One contains a small heel at $1 \%$ enrichment, the other a large heel at $\sim 5 \%$ enrichment. The operator examines the serial numbers on the DYMCAS printout to select the cylinder with the small heel, but mistakenly places the opposite cylinder on the cleaning stand. This sequence can perhaps be considered as one unlikely event. The operator then notes that Table 8-1 of IP RD 1.2.4 allows him to add up to 100 gallons of water. He adds more than five gallons, and both mass and volume controls have been exceeded because of only one error.

Example \#2A: Mass Error/Double Batching: It is assumed in this scenario that the mass of the heel ( $5 \%$ enrichment) in the cylinder is believed to be very low when in fact it exceeds a safe critical mass. This is perhaps an unlikely event, but considering recent problems with heel mass errors, such a determination is questionable. Through simple negligence, an operator then adds more than five gallons of cleaning solution. Both mass and volume controls have been exceeded.

Example \#2B: Mass Error/Solution Cannot be Withdrawn: This scenario is similar to the preceding example. The mass of the heel (5\% enrichment) in the cylinder is believed to be very low when in fact it exceeds a safe critical mass. Again this is perhaps an unlikely event. The operator adds five-gallons of initial wash solution. Because of the large heel mass, the resulting solution has a very low $\mathrm{H} / \mathrm{U}$ ratio and is therefore too thick to be withdrawn into Column C. The operator follows the instructions of IP RD 1.2.4 (I8.9.6) to remove as much solution as possible, which in this case is little or none at all. He then continues with the cleaning procedures and adds another five gallons. Both the mass and volume limits have again been exceeded.

In defense of the existing procedures, it is noted that IP RD 1.2.4 (I55.1.4 and I8.7.2) informs the operator not to add more than five gallons of solution unless specifically provided for in Table 8-1 of the procedures. Since the enrichment was 5\%, Table 8-1 does not allow the addition of more than five gallons. However, these sections of the procedure are not indicated as OSRs and are located several pages from the procedures describing how to withdraw solution. Failing to comply with this restriction appears to be a human error that does not qualify as an unlikely event.

Example \#3: Mass Error/Enrichment Error: As in the previous examples, the mass of the heel (5\% enrichment) in the cylinder is believed to be very low when in fact it exceeds a safe critical mass. The operator mistakenly believes that the enrichment is $2 \%$. This could result from an incorrect data entry in DYMCAS, a somewhat illegible printout, or simply misreading a 5 as a 2 . In this scenario, Table 8-1 of the IP allows the operator to add up to 25 gallons, and both mass and volume controls are exceeded.

Example \#4: Enrichment Error/Negligence with Volume Control: A cylinder with a known large heel mass is thought to have contained $\mathrm{UF}_{6}$ at $2 \%$ enrichment, when in fact the enrichment is really $5 \%$. Again, the cause of this error could be an incorrect data entry in DYMCAS, a somewhat illegible printout, or perhaps operator error (simply misreading a 5 as a 2 ). Whether this is an unlikely event is questionable. The operator 
notes that Table 8-1 allows him to add 25 gallons of wash solution, but he neglects to read the restriction at the top of the table, which limits its applicability for heel masses no more than 41 pounds. (Alternatively, he could just accidentally double batch the washing solution.) Both mass and volume controls have been exceeded.

\subsection{Summary}

In each of the above situations (there are no doubt others of slight variation), the loss of formal criticality controls appears to be possible with less than two unlikely events-a violation of the Double Contingency Principle. Although one can readily debate that some of the above errors are unlikely events, they do not appear to be significantly more unlikely than situations known to have occurred in X-705. The working environment in this facility is generally very warm, and personnel are required to wear several layers of clothing, including 2 pair of gloves. Such an environment is conducive to inattentive human error.

The application of mass and volume controls according to IP RD 1.2.4 is very detailed and hence subject to confusion and error in an operational environment. Recall that the mass control establishes a heel weight limit of 41 pounds - unless the enrichment is lower than a value given in Table 5-1 of the IP. Similarly, the volume control establishes a limit of five gallons on the wash solution-unless the heel mass is less than 41 pounds and the enrichment is lower than a value given in Table 8-1 of the operating procedure. To expect that an operator notes all the caveats of these procedures is not prudent.

Furthermore, the mass and volume controls are based on data provided in DYMCAS, and several substantial errors in this data base have been discovered over the past few years. For reasons not understood, rather large uncertainties have been discovered in the heel masses, and at least one significant enrichment error was identified. As a result, a simple human error of double batching the wash solution could result in the loss of all formal criticality controls.

It should be noted that the criticality controls are rather conservative. They do not consider, for example, that a small amount of boron or impurities (e.g., rust) in the heel will increase the critical mass/volume. Furthermore, as discussed in Sections 5.1.3 and 5.1.4, these mass and volume controls are based on a spherical geometry with water reflection. Although part of the heel may be reflected by the cylinder and a near-by operator, the assumption of a fully reflected sphere may be overly conservative, especially if the possibility of a "full" cylinder can be excluded. 


\section{RECOMMENDATIONS FOR FURTHER CONSIDERATION}

This section suggests several recommendations to be considered by MMES management in order to improve large cylinder cleaning operations. The majority of the attention is devoted to recommendations for improving nuclear criticality safety. During the preparation of this report, however, several efficiency-related issues were raised by operational personnel. Because attempts to improve efficiency of the cleaning process will no doubt raise additional criticality concerns, these issues are also briefly presented.

\subsection{Safety Issues}

\subsubsection{Assessment of Control by Soluble Poison}

The use of boric acid solution should be investigated in further detail to understand its benefits and shortcomings as a criticality control.

Considerable effort is devoted to the use of boric acid in the wash solution. As discussed in Section 5.1.5, however, several unresolved issues currently prevent its qualification as a principal safety control. Assuring that the ${ }^{10} \mathrm{~B}$ is initially present in the solution could be resolved in several ways. The most difficult issue to address is probably that of precipitation of the boron. Addressing this issue will require expertise in uranium chemistry and perhaps additional experiments.

Because of the impact of this issue on others listed below, it is recommended that the use of boron as a control be assessed at the earliest possible time.

\subsubsection{Simplification of Enrichment Controls}

Decisions based on enrichments should be minimized.

During the cylinder cleaning process, at least three decisions are made based on enrichment. These include the heel mass that can be present, the volume of solution that can be added, and the uranium concentration that permits steam cleaning. IP RD 1.2.4 currently allows nine different quantities of wash solution (based on enrichment) if the heel weight is less than 41 pounds. Although some simplification of decisions based on enrichment has occurred in the past two years, the issues most affecting criticality safety have not been addressed.

The use of enrichment as a multi-parameter control has two disadvantages. First, it adds complexity to the decision process and increases the opportunity for human error simply by confusing required criteria. Second, an error made in the enrichment often invalidates the criteria on which the decision itself is based.

Section 6.3 discussed several undesirable scenarios that could result from basing mass and volume controls on detailed enrichment criteria. The working environment in X-705, as noted earlier, is conducive to human error. It is strongly recommended that enrichment criteria similar to those in ANSI N14.1 be considered.

\subsubsection{Investigation of Heel Weight Errors}

A thorough investigation should be initiated to determine the cause of the observed large errors in heel weight. 
Ref. 24 indicates considerable effort is taken to ensure heel-weight accuracy. Nevertheless, as mentioned earlier, one cylinder cleaned in the recent past appeared to have a heel of -41 pounds, another currently shows -35 pounds. Although negative heel weights (up to -10 pounds) are acceptable according to this OM, the heel weights of these cylinders were significantly outside the limit. The fact that such large heel-weight errors have occurred is very disturbing and questions the validity of mass control.

In addition to the weighing procedures themselves, the exact manner and verification of entries in DYMCAS are likewise important, since these values are taken as a given by operational personnel. Depending on the results of this investigation, check-weighing of the cylinders may be desirable. Heeled cylinders generally remain in storage for at least six months to allow daughter products to decay. Check-weighing the cylinder just prior to movement into X-705 would provide an independent measurement.

\subsubsection{Restrictions on Cylinders with Large Heels}

Procedures should be implemented to ensure that cylinders with known large heels are not taken to X-705 (or stored where they could be inadvertently taken into the facility) without special arrangement.

Under normal conditions, the heel weight of a cylinder should be very low. With perhaps the exception of a faulty valve, the inability to remove almost all the $\mathrm{UF}_{6}$ indicates a major problem or very careless procedures. Furthermore, cylinders do not just appear at X-705 for decontamination. Considerable coordination is required among chemical operations, material handling, and material accountability personnel. If any of these personnel observe a cylinder with a large heel, such a cylinder should be flagged immediately for special handling.

The presence of a large-heel cylinder in X-705 significantly increases the possibility of an accident (e.g., confusing it with another cylinder, misreading the heel mass, not complying with procedures, etc.). The extra precautions and special handling, which should be required very infrequently, would be worth the safety benefit gained. DM-868, Rev. 4, previously required NCS to be consulted if the heel mass exceeded either a given mass or enrichment; the mass restriction (for some enrichments) was removed in later documents.

\subsubsection{Hardware Modifications to Prevent Double Batching}

Hardware modifications to prevent double batching by simple human error should be considered.

The use of the clear vertical columns (i.e., Column A) to add cleaning solution to the cylinder is susceptible to double batching errors by an inattentive operator. Several hardware changes (such as those used at Paducah) should be evaluated if volume control is to remain as a basis for criticality safety.

\subsubsection{Further Evaluation of Double Batching Accident}

Consequences of double batching should be examined in more detail.

As noted in Sections 5.1.4 and 6.4, the subcritical volume limit of five gallons of water is based on a spherical, water-reflected heel. Although part of the heel may be reflected by the cylinder and a near-by operator, the assumption of a fully reflected sphere may be overly conservative. A more realistic analysis may demonstrate that 
achieving a critical configuration as a result of simple double batching (adding 10 gallons instead of five gallons) is still an unlikely event, especially if the possibility of a "full" cylinder can be excluded. Obviously, such an analysis should be carefully reviewed.

\subsubsection{Clarification of Safety-Related Issues in IP RD 1.2.4}

Several safety-related issues should be clarified in IP RD 1.2.4 as soon as possible if the appropriate sections are not updated because of other recommendations.

- g[5.1.3 authorizes cleaning of cylinders with large heels with concurrence of supervision. Concurrence should be clarified.

- $\quad \mathbb{1 5} 1.2, \mathbb{T 5} 1.4, \mathbb{1 5} 1.6, \mathbb{1 5} .1 .7$, and $\mathbb{1 5} .1 .10$ should be designated as administrative controls important to criticality safety, if they are intended to be so.

- I8.9.6 should provide clarifying instructions on what to do if the solution cannot be withdrawn.

\subsubsection{Use of a Boroscope}

Evaluate the safety benefit of using a boroscope to examine the inside of large cylinders scheduled for cleaning.

As noted earlier, a video device was recently utilized at PORTS to permit examination of the inside of a large cylinder. Although the purpose of this device was apparently to view the physical properties of the UF6 as it cooled in a full cylinder, this device could have a safety benefit for cylinder cleaning operations. It appears to be especially useful for unusual situations such as those noted with cylinders \#4A001118 and \#4A001106:

\subsubsection{Minor Changes to IP RD 1.2.4}

Several minor discrepancies in IP RD 1.2.4 should be corrected.

The preparation and review of a detailed procedure are much more complex than is often appreciated. It is very difficult to ensure that all situations are covered and that obvious steps are not overlooked. This is especially true when procedures are repeated until a given condition is satisfied. The comments below are generally very minor but added here for completeness. (This list itself may not be complete.)

- 95.1.3 does not explain the action to be taken if Table 5-1 is not satisfied.

- T5.1.6 precludes the cleaning of two 30 -in. cylinders at the same time, but not the cleaning of two large cylinders of different sizes.

- I5.1.10 is not completely consistent with I8.14.1. It is doubtful the operator would calculate $\mathrm{ppm}{ }^{235} \mathrm{U}$ given $\mathrm{ppm} U$ from the laboratory.

- T6.5 allows eight large cylinders in X-705 at the same time. The need for more than a few is not apparent, and a reduction would decrease possible confusion.

- $\$ 8.3 .7$ results in the opening of the steam valve. No subsequent step instructs the operator to close it.

- Tables 5-1 and 8-1 are ambiguous at the enrichment discontinuities.

- T8.13.13 and T[8.15.3 appear to be filling Column $\mathrm{C}$ with solution before it is emptied. 
- During one of the three recent red-line changes, the first word in I8.14.15 was inadvertently changed from "Record" to "Remove."

\subsection{Efficiency-Related Issues}

During the preparation of this report, operational personnel expressed a desire to modify cylinder cleaning procedures in order to reduce cleaning time. In general, these changes have criticality implications. Several of these efficiency-related issues are presented below in the form of questions for consideration by MMES management.

- Can the volume of cleaning solution be increased above five gallons during the wash/rinse process (not necessarily on the first wash)?

- Can steam cleaning be used earlier in the wash cycle? (Currently it appears as if it cannot begin until after the first rinse, and then only with boric acid solution.)

- Does the uranium concentration really need to be less than $1000 \mathrm{ppm}$ to begin rinsing?

- Does the cylinder need to be rinsed until the uranium concentration is less than $500 \mathrm{ppm}$ ? 


\section{REFERENCES}

1. Sheaffer, M. K. and S. C. Keeton. Introduction to the Nuclear Criticality Safety Evaluation of Facility X-705, Portsmouth Gaseous Diffusion Plant, UCRL-ID114900, Lawrence Livermore National Laboratory, Livermore, California, August 16, 1993.

2. Gastelle, D. G. Internal Cleaning of 21/2, 10, and 14-Ton Cylinders, IP RD 1.2.4, Rev. 4, Ch A-C, Chemical, Utilities, and Power Division, Chemical Operations, March 6, 1992.

3. GAT/GDP-1073, Portsmouth Gaseous Diffusion Plant Final Safety Analysis Report, Volume 1-3, April 1985.

4. Feuerbacher, J. L. Nuclear Criticality Safety in the X-705 Decontamination and Recovery, and Related Areas, GAT-DM-868, Rev. 4, Goodyear Atomic Corporation, December 1984.

5. Lewis, K. D. Nuclear Criticality Safety in the X-705 Decontamination and Recovery, and Related Areas, GAT-DM-868, Rev. 4, Add. 1, Goodyear Atomic Corporation, May 5, 1986.

6. Decontaminating 2.5-, 10-, and 14-Ton Cylinders, X-705, Criticality Hazards Facility Change Agreement FCA-382, August 22, 1989.

7. Operational Safety Requirements for X-705 Decontamination Building, GAT/ GDP-1074, Part H, Rev. 3, Production Services Department, Portsmouth Gaseous Diffusion Plant, April 22, 1985.

8. Bowser, P. K. Guidelines-Disaster Plan-Maximum Withdrawal, CE 10.2.2, Rev. 2, Add. 1, Operations Division, Cascade Operations, September 24, 1985.

9. Withdrawal of Greater than 4.5\% U-235 Material into 48X 10-Ton Cylinders (ERP, LAW), Criticality Hazards Facility Change Agreement FCA-523, August 8, 1991 .

10. Newvahner, R. L. Nuclear Criticality Safety Study of Loss of Moderation Control in 10-Ton and 21/2 Ton UF 6 Cylinders by KENO V.a Computer Code Analyses, POEF-T-3495, Martin Marietta Energy Systems, Piketon, Ohio, December 1991.

11. Tayloe, R. W. Jr. et al. Nuclear Criticality Safety Analysis for Increased Enrichment Limit in 10-Ton (48X) UF 6 Cylinders, POEF-T-3563, Battelle, Columbus, Ohio, May 10, 1991.

12. Tayloe, R. W. Jr., et al. Nuclear Criticality Safety Study for Increased Enrichment Limit in 21/2-Ton (30B) UF 6 Cylinders, POEF-T-3597, Battelle, Columbus, Ohio, December 1992.

13. American National Standard for Nuclear Materials, Uranium HexafluoridePackaging for Transport, ANSI N14.1-1990, Institute of Nuclear Materials Management, New York, New York, June 21, 1990. 
14. American National Standard for Nuclear Criticality Safety in Operations. with Fissionable Materials Outside Reactors, ANSI/ANS 8.1-1983, American Nuclear Society, LaGrange Park, Illinois, October 7, 1983.

15. Uranium Hexafluoride: A Manual of Good Handling Practices, ORO-651, Rev. 6, Analysis Corporation, Oak Ridge, Tennessee, October 1991.

16. Shippers-General Requirements for Shipments and Packagings, Title 49, Code of Federal Regulations, Part 173, U. S. Department of Transportation, 1994.

17. Packaging and Transportation of Radioactive Material, Title 10, Code of Federal Regulations, Part 71, U. S. Nuclear Regulatory Commission, 1994.

18. Hazardous Material Packaging for Transport-Administrative Procedures, DOE Order 1540.2, U.S. Department of Energy, September 30, 1986.

19. Safety Requirements for the Packaging and Transportation of Hazardous Materials, Hazardous Substances, and Hazardous Wastes, DOE Order 5480.3, U. S. Department of Energy, July 7, 1985.

20. Feuerbacher, J. L. Nuclear Criticality Safety Guide for the Portsmouth Gaseous Diffusion Plant, GAT-225, Rev. 4, Goodyear Atomic Corporation, March 15, 1981.

21. Thomas, J. T. Nuclear Safety Guide, TID-7016, Rev. 2, Oak Ridge National Laboratory, Oak Ridge, Tennessee, June 1978.

22. Jordan, W. C. and J. C. Turner, Minimum Mass of Moderator Required for Criticality of Homogeneous Low-Enriched Uranium Systems, ORNL/CSD/TM284, Oak Ridge National Laboratory, Oak Ridge, Tennessee, December 1992.

23. American National Standard Use of Borosilicate-Glass Raschig Rings as a Neutron Absorber in Solutions of Fissile Material, ANSI/ANS .8.5-1979, American Nuclear Society, LaGrange Park, Illinois, October 9, 1979.

24. Stepp, B. S. Weight Verification, RMH 15.1-1, Add. 2, Uranium Materials Handling, May 25, 1982.

25. Safety of Nuclear Facilities, DOE Order 5480.5, U. S. Department of Energy, September 23, 1986.

26. Nuclear Criticality Safety, DOE Order 5480.24, U. S. Department of Energy, August 12, 1992. 
APPENDIX A: FLOWCHARTS OF LARGE CYLINDER CLEANING PROCEDURES 


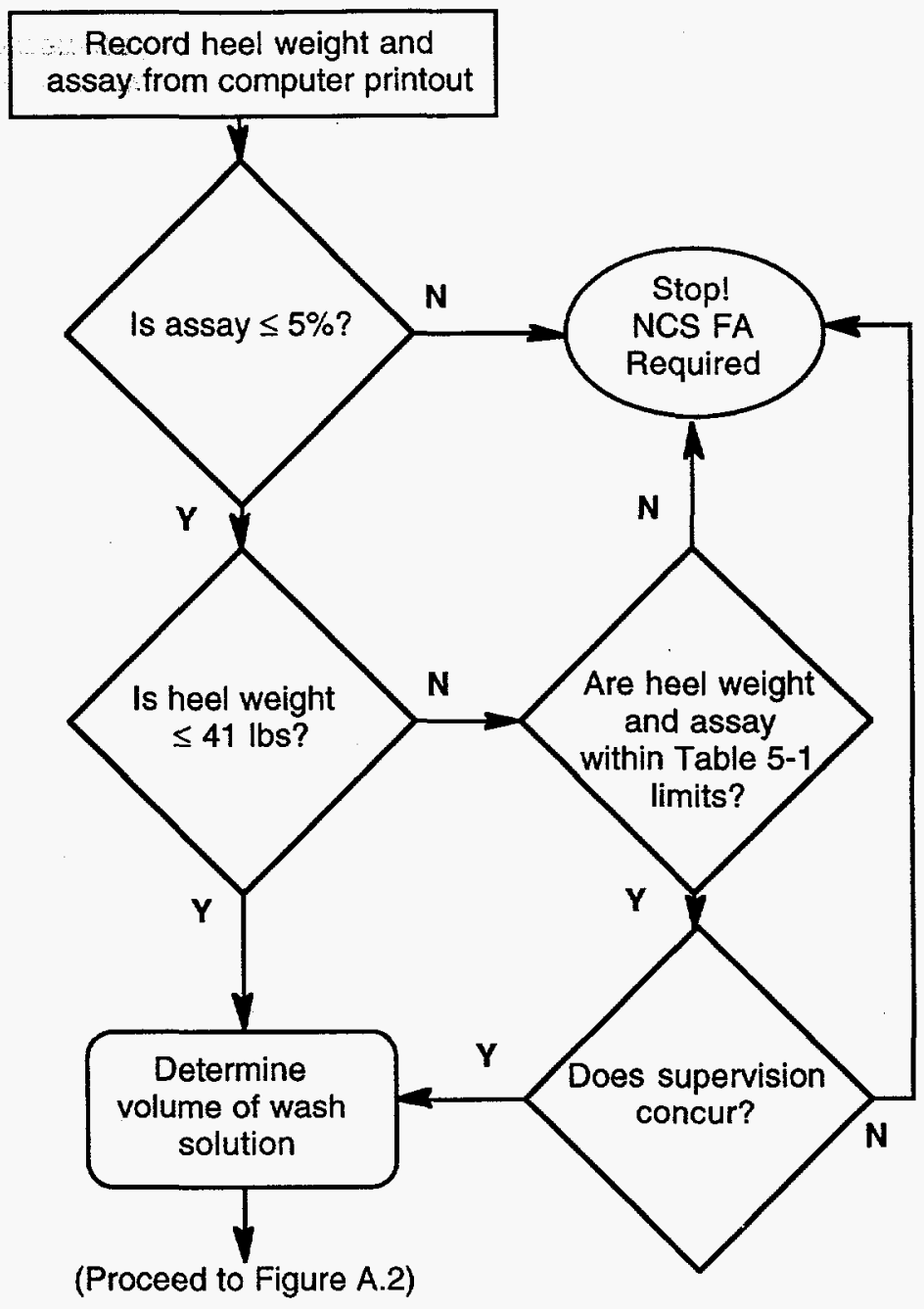

Figure A.1. Determining allowed heel weight in cylinder to be cleaned. 


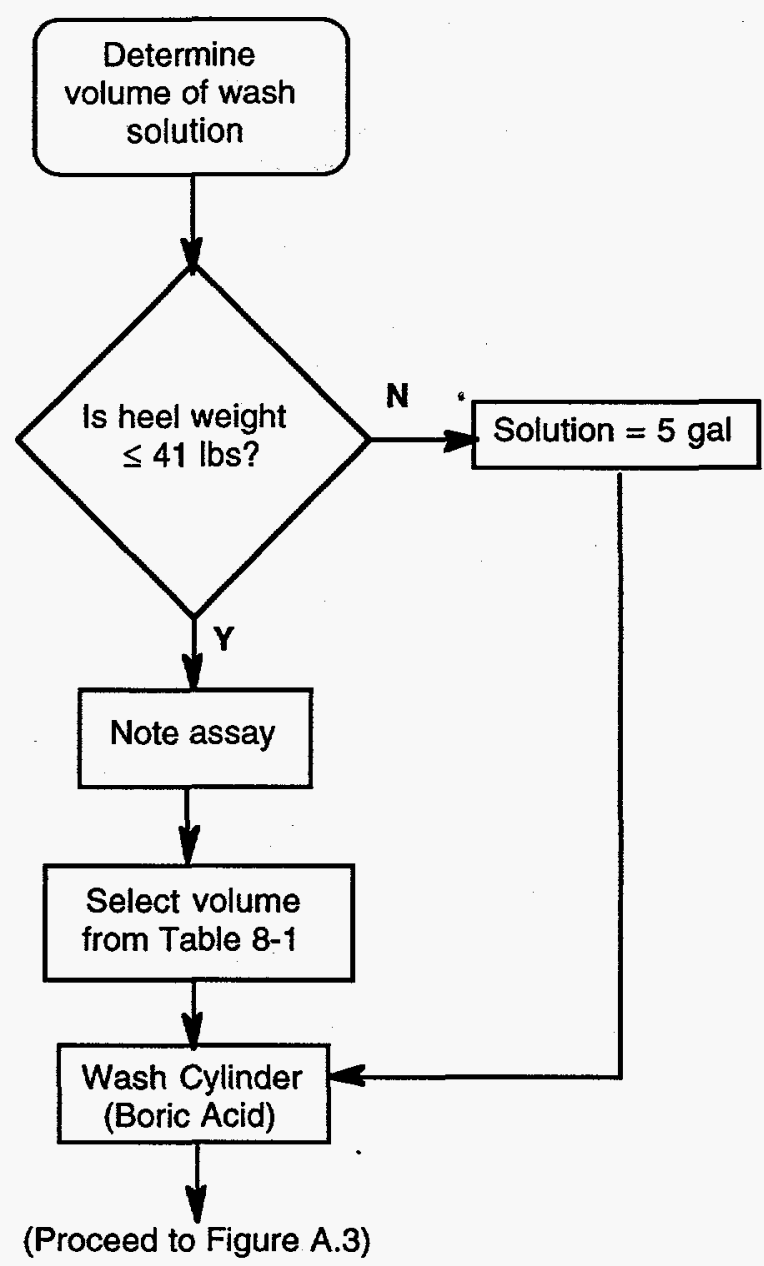

Figure A.2. Determining allowed volume of cleaning solution. 


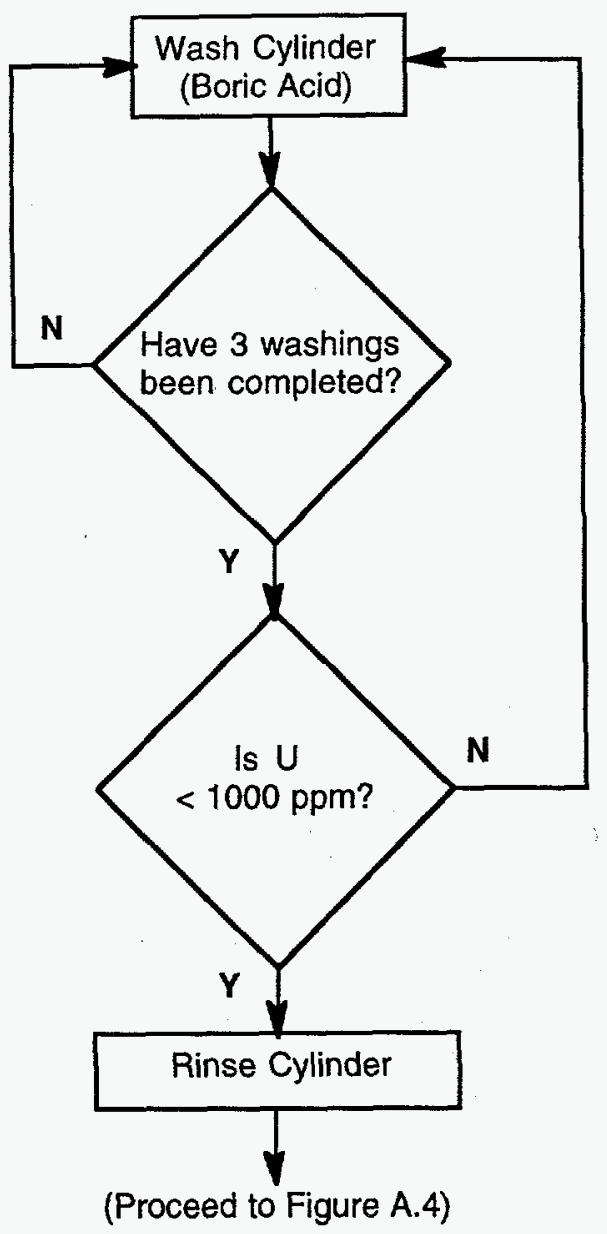

Figure A.3. Procedures for cylinder washing. 


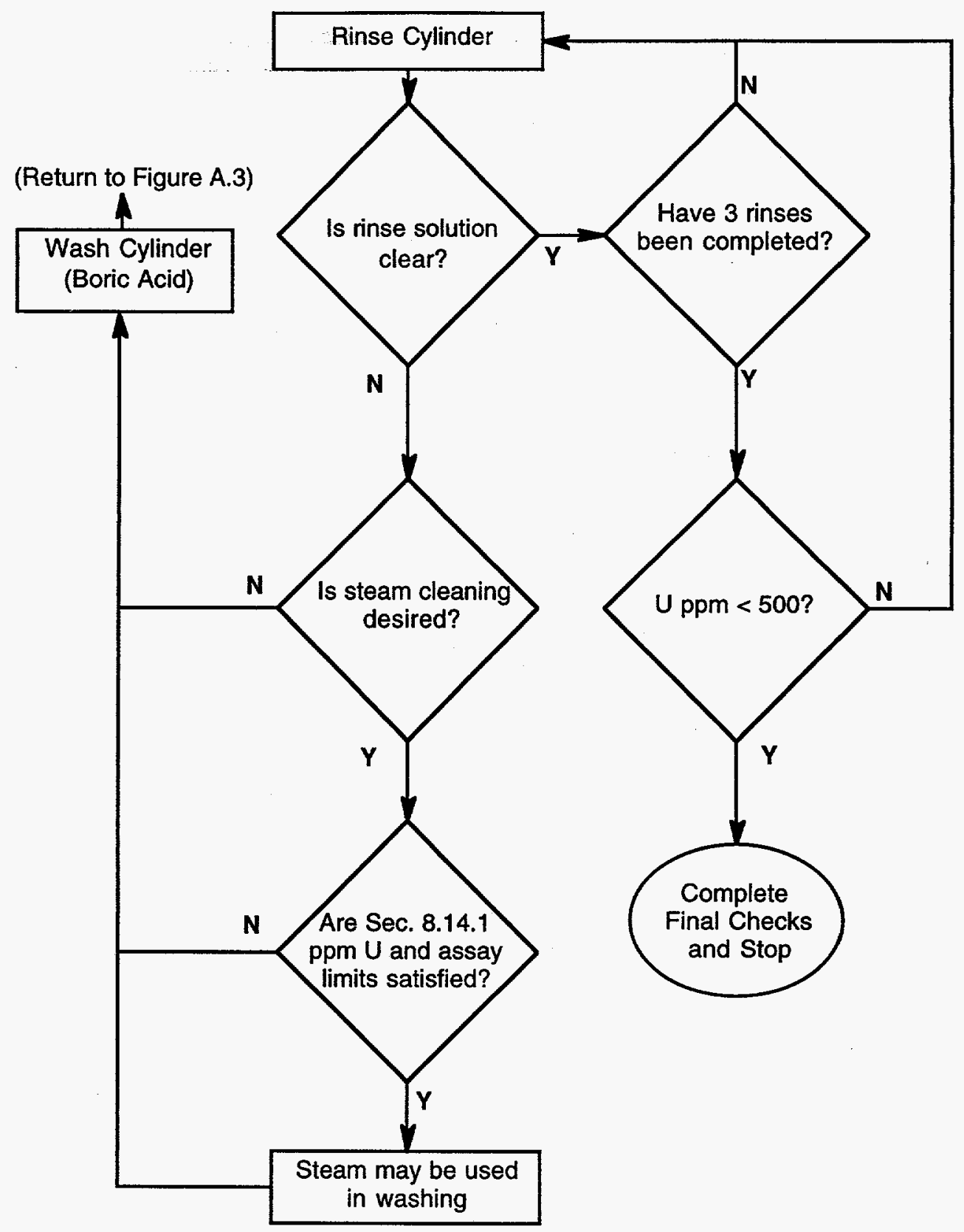

Figure A.4. Procedures for cylinder rinsing. 